\title{
1 Disc and Actin-Associated Protein 1 Influence Attachment in the Intestinal Parasite
}

\section{Giardia lamblia}

3 Melissa C. Steele-Ogus ${ }^{1}$, Ava M. Obenaus ${ }^{2}$, Nathan J. Sniadecki ${ }^{2}$, and Alexander R. Paredez ${ }^{1}$

$4 \quad{ }^{1}$ Department of Biology, University of Washington, Seattle, United States

$5 \quad{ }^{2}$ Department of Mechanical Engineering, University of Washington, Seattle, United States

7 Abstract

The deep-branching eukaryote Giardia lamblia is an extracellular parasite that attaches to

9 the host intestine via a microtubule-based structure called the ventral disc. Control of attachment

10 is mediated in part by the movement of two regions of the ventral disc that either permit or

11 exclude the passage of fluid under the disc. Several known disc-associated proteins (DAPs)

12 contribute to disc structure and function, but no force-generating protein has been identified

13 among them. We recently identified several Giardia actin (GlActin) interacting proteins at the

14 ventral disc, which could potentially employ actin polymerization for force generation and disc

15 conformational changes. One of these proteins, Disc and Actin Associated Protein 1 (DAAP1), is

16 highly enriched at the two regions of the disc previously shown to be important for fluid flow

17 during attachment. In this study, we investigate the role of both GlActin and DAAP1 in ventral

18 disc morphology and function. We confirmed interaction between GlActin and DAAP1 through

19 coimmunoprecipitation, and used immunofluorescence to localize both proteins throughout the

20 cell cycle and during trophozoite attachment. Similar to other DAPs, the association of DAAP1

21 with the disc is stable, except during cell division when the disc disassembles. Depletion of

22 GlActin by translation-blocking antisense morpholinos resulted in both impaired attachment and

23 defects in the ventral disc, indicating that GlActin contributes to disc-mediated attachment. 
24 Depletion of DAAP1 through CRISPR interference resulted in intact discs but impaired

25 attachment, gating, and flow under the disc. As attachment is essential for infection, elucidation

26 of these and other molecular mediators is a promising area for development of new therapeutics

27 against a ubiquitous parasite.

\section{Author Summary}

Giardia lamblia is a single-celled organism and one of the most common gastrointestinal

31 parasites worldwide. In developing countries, recurrent Giardia infections are common, due to

32 lack of access to clean water. Giardia infections can lead to diarrhea, vomiting, dehydration,

33 disruption of the intestinal microbiome, and chronic infections can lead to irritable bowel

34 syndrome. Because existing drug treatments have side effects and Giardia's resistance to drugs

35 is increasing, new treatment strategies are needed. The parasite's attachment to the host's

36 intestine is mediated by a Giardia-specific structure that resembles a suction cup and is called

37 the ventral adhesive disc. We previously identified DAAP1, a protein which interacts with

38 Giardia actin and localizes to the ventral disc. Here, we explore the relationship between these

39 two proteins and investigate their role in disc-based attachment. Most disc proteins, including

40 DAAP1, are unrelated to any human proteins, making them appealing drug targets to inhibit

41 parasite attachment and infection.

\section{Introduction}

44 Giardia lamblia, a single-celled parasite, is the cause of over 280 million annual cases of

45 the gastrointestinal disease giardiasis worldwide [1,2] This extracellular parasite colonizes the

46 lumen of the intestine, where its ability to maintain infection requires tight attachment to 
47 microvilli, in order to withstand the peristaltic flow of the gastrointestinal tract [3]. The primary

48 means of attachment is via a specialized microtubule-based organelle known as the ventral

49 adhesive disc [4-6]. A well-functioning disc is critical for cell survival and disease transmission

50 [7], but the molecular mechanisms controlling conformational dynamics and function remain

51 poorly understood.

Imaging of fluid flow at the disc margin identified two areas postulated to be important

53 for tight attachment: one at the anterior and the other at the posterior of the disc [8-10] (Figure

54 1A). The former is the marginal region of the overlap zone, the region of the disc where the sheet

55 of microtubules overlaps itself. The other is the ventral groove, a hump in the posterior region of

56 the disc where the ventral flagella exit between the disc and cell body. Interruption of contact in

57 these areas results in disruption of attachment and in fluid moving underneath the disc $[9,11,12]$.

58 Cryo-electron tomography imaging of the disc reveals different protein densities in these areas,

59 indicating specialized architecture within the disc itself, which may indicate that specific effector

60 proteins control disc conformation and fluid flow [13]. In the current model, both hydrodynamic

61 flow and suction contribute to the mechanism of attachment [9]. Attachment occurs in several

62 distinct stages [8,9]. In early attachment, the anterior ventrolateral flange, lateral crest and

63 ventral groove make contact with the surface while the ventral flagella beat to generate fluid

64 flows. During this stage cells can either skim the surface or remain stationary. In the later stages

65 of attachment, the cell body becomes more intimately associated with the surface so that the

66 lateral shield and bare area make contact with the surface and the cells remain in place. Flagella-

67 beating is required for initiation, but not maintenance, of attachment, indicating that fluid must

68 be moved out from underneath the disc during the earlier stages of attachment $[9,14]$. 
These conformational changes in the disc which control attachment are not generated by

70 microtubule turnover, as microtubule depolymerizing or stabilizing drugs do not affect

71 attachment [15]. Though microtubules are the foundation of the disc, it is also composed of over

72100 other proteins, known as disc-associated proteins (DAPs). At least five of these DAPs have

73 been shown to be important for disc biogenesis and function $[9,12]$. Only three DAPs identified

74 to date contain known microtubule-binding motifs; most are ankyrin-repeat proteins, NEK

75 kinases, or the annexin-like alpha-Giardins [15,16]. At least 25, however, lack identifiable

76 domains and are annotated in the Giardia genome as "hypothetical proteins" $[17,18]$. So far, no

77 DAPs have been identified as motor or force-generating proteins. Thus, the proteins that mediate

78 changes in disc conformation are unknown.

79 Actin has a conserved role in force generation and in controlling cell and organelle shape

80 in eukaryotic cells[19]. Previously, localization studies using heterologous antibodies

81 demonstrated that Giardia actin (GlActin) and actin regulators associate with the ventral disc

$82[6,20]$. This observation led to multiple experiments attempting to test the role of GlActin in

83 attachment using actin inhibitors. These studies yielded conflicting results because reagents that

84 typically recognize actin or actin-binding proteins in other organisms were presumed to act

85 similarly in Giardia [6]. Later, GlActin was determined to be one of the most divergent actins

86 found among eukaryotes and its genome lacked genes encoding conventional actin-binding

87 proteins that were reportedly localized to the disc [21-23]. Further research revealed that

88 GlActin has non-conservative amino acid substitutions, predicted to disrupt actin inhibitor

89 binding, and anti-GlActin antibodies revealed localization throughout the cell [22]. Thus,

90 GlActin's potential role in disc-based attachment is controversial. 
We recently identified eight Giardia actin (GlActin) interactors that localize to the

92 ventral disc [18], suggesting a means to resolve the role of actin and actin-binding proteins in

93 ventral disc function. One such actin-interacting protein, GL50803_16844, which we denote

94 Disc and Actin Associated Protein 1 (DAAP1), appears highly enriched in the two regions of the

95 disc important for regulating fluid flow during attachment.

96 In this study, we use morpholinos and CRISPR interference (CRISPRi) to deplete

97 GlActin and DAAP1 respectively and investigate the role of both proteins in the ventral disc.

98 Our results show that GlActin plays a role in normal ventral disc morphology and both GlActin

99 and DAAP1 are required for parasite attachment.

\section{$101 \quad$ Results}

102 GlActin affects attachment and disc morphology

103 In vitro, Giardia normally grows attached to the inside of a culture tube. We used an

104 antisense translation-blocking morpholino to deplete GlActin for 24 hours, [22] after which we

105 assessed their attachment. We compared the numbers of cells attached to the tube wall to cells

106 unattached in the media for each condition. With an approximately 50\% knockdown (Figure S1),

107 we found attachment to plastic culture tube walls to be significantly decreased, with an average

108 of $23 \%$ of cells attached compared to $75 \%$ of cells treated with a control morpholino (Figure

109 1B). Dead Giardia cells lose their ability to adhere to culture tubes. To account for the possibility

110 that the majority of the unattached cells were dead, we stained the unattached cells with

111 propidium iodide to mark dead cells, and fluorescein diacetate to mark live cells. While slightly

112 more unattached GlActin knockdown cells were dead compared to that of the control population, 
113 this difference was not statistically significant (Figure 1C), indicating that the defect in

114 attachment in GlActin-depleted cells was not due to a preponderance of dead cells.

115 We asked if the role of GlActin in attachment could be attributed to an effect on the

116 ventral disc. Attached and unattached cells were treated with either control or anti-GlActin

117 morpholino, fixed after $24 \mathrm{~h}$, and examined for distribution of a ventral disc marker using

118 immunofluorescence microscopy. We used a HALO-tagged delta-giardin which is widely

119 distributed in the disc to monitor whether the disc appeared normal or defective. Defects were

120 then further classified as 1) mild, with misshapen/broken discs or small gaps in the disc or 2)

121 severe, including unwound discs or severely misshapen discs (Figure S2, 1D, 1E). More GlActin

122 knockdown cells had defective discs compared to those in the control; however, this difference

123 was only significant in unattached cells (Figure 1D, 1E). While both attached and unattached

124 GlActin-depleted cells had more disc defects than their counterparts treated with the control

125 morpholino, the unattached GlActin-depleted cells had the most defective discs among all the

126 categories. Yet, there were more unattached cells than cells with disc defects, suggesting that

127 GlActin has a role in attachment beyond its contribution to disc morphology.

$129 G l$ Actin interacts with disc-associated protein DAAP1

130 We next asked if GL50803_16844, previously identified by mass spectrometry as a

131 potential actin filament interactor at the ventral disc [18], could be involved in attachment.

132 GL50803_16844 is conserved in all Giardia lamblia isolates and Giardia muris, but is absent

133 from the genome of Spironucleus, a close relative of Giardia which lacks a ventral disc [24].

134 Hereafter, we will refer to this protein that lacks identifiable domains and homologues in other

135 organisms as Disc- and Actin-Associated Protein 1 (DAAP1). We tagged DAAP1 with a C- 
136 terminal 3xHA tag and expressed it episomally in Giardia (Figure S2). Immunoprecipitation of

137 this construct revealed it in complex with GlActin (Figure 2A). We also endogenously tagged

138 DAAP1 with a C-terminal mNeonGreen tag then used live and fixed cell fluorescent imaging.

139 Notably, this fusion protein localizes to the entirety of the disc, but it is highly enriched in the

140 ventral groove and the overlap zone, two areas implicated in attachment (Figure 1A, 2B).

141 Flexion of the overlap zone can be seen during detachment from the surface, consistent with the

142 notion that conformational changes of specific regions of the disc can regulate attachment

143 (Supplemental Movie 1).

144 To investigate co-localization between GlActin and DAAP1, we calculated Pearson's

145 correlation coefficients for these two proteins using the JACoP plugin for ImageJ [25,26]. While

146 DAAP1-mNeonGreen does not appear to co-localize with GlActin during interphase, in mitosis

147 DAAP1 leaves the ventral disc and was observed to co-localize with GlActin (Figure 2C).

148 We also measured the intensity of DAAP1-mNeonGreen fluorescence in GlActin-

149 depleted cells, selecting a region in the ventral groove, as that is where DAAP1 expression in the

150 highest (Figure 3). While there was no significant difference between fluorescence levels in

151 attached cells (Figure 3A, 3B), this difference was significant in unattached cells (Figure 3C,

152 3D). Furthermore, in some GlActin-depleted cells, we observed DAAP1 loss of enrichment in

153 the entire disc (Figure 3C). These results indicate that GlActin is responsible for DAAP1 disc

154 localization.

155 The microtubules in the ventral disc are stable and do not undergo dynamic instability;

156 they rely on a set of core DAPs to maintain this stability [15]. During mitosis, the disc is

157 dismantled as the cells must detach to "swim" away from each other during cytokinesis $[27,28]$.

158 New discs in the daughter cells appear during early cytokinesis and are built from microtubules 
159 originating from the mother disc and the median body [27,29]. Notably, DAAP1-mNeonGreen

160 remains on the disc during telophase, late into disassembly, and begins to coalesce again on the

161 daughter discs in mid cytokinesis. In newly-divided cells, DAAP1-mNeonGreen has returned to

162 its disc localization and is once more enriched in the ventral groove (Figure 2C). Fluorescence

163 recovery after photobleaching (FRAP) confirmed the stability of DAAP1-mNeonGreen for disc

164 localization, as fluorescence levels did not recover for 12 minutes after photobleaching (Figure

1654 ) in either of the two regions of the disc where DAAP1 is enriched. Viability was confirmed by

166 cell movement as seen in Supplemental Movie 2. This result is similar to the fluorescence

167 recovery of other DAPs. Taken together, these data indicate that DAAP1 is a GlActin interactor

168 and stably localized to the ventral disc in interphase.

\section{DAAP1-depleted cells have intact ventral discs}

Since GlActin is involved in both attachment and disc morphology, we asked if DAAP1

172 could have a similar role. We attempted depletion of DAAP1 with translation-blocking

173 morpholinos, however, the sequence was design-resistant and the knockdown level inconsistent.

174 We then turned to CRISRPi to investigate DAAP1's potential role in attachment and disc

175 morphology. To monitor disc morphology as well as deplete DAAP1, we inserted the HALO-

176 tagged delta-giardin marker into the dead Cas9- (dCas9) based CRISPRi plasmid and introduced

177 this into a DAAP1-mNeonGreen expressing cell line. This allowed us to evaluate knockdown on

178 both a whole population (Figure 5A) and an individual cell basis. We analyzed the fluorescence

179 of endogenously-tagged DAAP1-mNeonGreen in control cells expressing dCas9 with a non-

180 specific guide RNA to those expressing a DAAP1 specific small guide RNA resulting in an

181 average decrease in expression of $40 \%$ for the population. We once again separated cells that 
182 were attached to culture tubes from unattached cells to probe for disc defects in each

183 subpopulation. We did observe a higher proportion of disc defects in the DAAP1-depleted cells

184 than in the control, but this difference was not significant (Figure 5B and 5C). These results

185 indicate that a $40 \%$ depletion of DAAP1 did not impact gross ventral disc morphology, as

186 assessed by light microscopy.

Inability to Maintain Attachment in DAAP1-Depleted Cells

DAAP1 knockdown cells had no visible defects, so DAAP1 may not be needed for disc assembly. To investigate a possible role in attachment, we used the aforementioned attachment assay on DAAP1-depleted cells and observed a small but significant decrease in attachment for two of three replicates relative to control cells (Supplemental Table 2). As CRISPRi is known to have variable penetrance in Giardia [30], we analyzed the fluorescence in unattached and

194 attached cells separately. Here we found reduced levels of DAAP1-mNeonGreen in unattached 195 cells compared to attached ones (Figure 6A). This result prompted us to further explore the 196 possible role of DAAP1 in attachment using a shear force attachment assay. In their normal 197 intestinal habitat, Giardia must maintain attachment even when subjected to the flow of chyme.

198 With this in mind, we challenged DAAP1-depleted cells with a fluid shear force. DAAP1-

199 depleted and control cells were allowed to attach inside a flow chamber and then subjected to a

200 flow of growth medium. Cell position and velocity were tracked using Trackmate (Figure 6B,

201 [31]). DAAP1-depleted cells slid significantly faster under flow than their control counterparts

202 (Figure 6C, 6D). Furthermore, more control cells remained in the field of view than DAAP1-

203 depleted cells over time (Figure 6E), indicating a better ability to maintain attachment. 


\section{Impaired Seal Formation in DAAP1-Depleted Cells}

We then hypothesized that the impaired attachment in DAAP1-depleted cells may be due

207 to impairments of the ventral groove or overlap zone "gates" that control fluid flow and buildup

208 of negative pressure differentials under the disc. We used fluorescent microspheres to investigate

209 this fluid flow in live, attached cells imaged in normal growth media. We found that spheres

210 entered under the disc more frequently in DAAP1-depleted than dCas9 control cells, consistent

211 with a defect in gating flow under the disc (Figure 7A). Furthermore, we found more beads per

212 cell in the DAAP1-depleted cells (Supplemental Table 4).

213 Since the ability of the gates to close affects disc seal formation $[8,14]$, we used plasma

214 membrane stain, CellMask Orange and Total Internal Fluorescence (TIRF) microscopy to

215 evaluate seal formation for DAAP1-depleted and dCas9-Control cells. This approach allowed us

216 to assess the different levels of attachment based on which portions of the cell were in contact

217 with the surface. Since stage 1 of attachment is unattached skimming, we omitted these cells

218 from our analysis, and only included cells in stage 2 (lateral crest contact), stage 3 (lateral shield

219 contact), and stage 4 (bare area contact). We found more cells at stages 2 and 3 and fewer in

220 stage 4 for DAAP1-depleted cells than in the dCas9-Control (Figure 7B), indicating impaired

221 seal formation around the ventral disc. Taken together, these data demonstrate that DAAP1

222 functions at the disc gates that regulate fluid flow and ventral disc seal formation.

\section{Discussion}

225 Here, we have confirmed that GlActin has a role in ventral disc morphology and disc-

226 based attachment (Figure 1). We also show that GlActin interactor DAAP1 is a stable component 
227 of the ventral disc (Figure 4). While perturbation of DAAP1 levels was not associated with

228 visible effects on disc morphology, it resulted in decreased attachment (Figures 5-7).

229 The ventral disc is well known as a Giardia-specific microtubule based structure $[17,32]$

230 and our data show that the actin cytoskeleton has an important role in ventral disc assembly and

231 function. A functional relationship between actin and microtubules has been well-documented

232 for other structures. In Chlamydomonas, actin is required for intraflagellar transport [33,34].

233 Actin monomers are a key component of the flagella through interaction with the inner dynein

234 arm [35-38] and recent evidence indicates actin is a component of the gamma-tubulin ring

235 complex [39]. Actomyosin interactions influence the orientation of the mitotic spindle [40,41]

236 and F-actin associates directly with mitotic spindles in Xenopus and starfish embryos [42,43].

237 Actin is also involved in microtubule- or tubulin-based host interaction in other parasites. For

238 instance, one of Toxoplasma gondii's formins localize exclusively to the conoid [44], a

239 latticelike organelle composed of tubulin which initiates host invasion [45]. There is evidence of

240 coordination between the microtubules of Toxoplasma's glideosome, which is used for actin-

241 based motility, during host invasion [46]. Furthermore, actin polymerization is believed to

242 contribute to conoid extrusion [47,48], and the conoid-localized Myosin H is essential for entry

243 and exit from host cells [49,50]. GlActin polymerization could have an analogous role in

244 controlling the movement of the ventral disc to facilitate attachment.

245 We also observed defects in the ventral disc in our GlActin-depleted cells (Figure 1),

246 which we characterized as either mild (misshapen, broken, or with small gaps) or severe

247 (unwound, severely misshapen, often associated with cytokinesis defects). There are several

248 possible explanations for these phenotypes. During mitosis, the ventral disc is dismantled and

249 two daughter discs are rebuilt during cytokinesis [27]. One possibility is that GlActin has a role 
250 in loading proteins on the assembling disc. GlActin also likely contributes to ventral disc

251 positioning, since actin has a role in positioning basal bodies that nucleate the disc [51,52].

252 However, many of the cells with defective discs have normally-positioned flagella (Figure 1,

253 Figure S2), indicating defective discs are not entirely due to basal body mispositioning. While

254 the resolution of light microscopy limits our ability to see details in the microtubule array of the

255 disc [53], over 25\% of our unattached GlActin-depleted cells lacked noticeable defects (Figure

256 1). Therefore, a portion of the attachment defect cannot be attributed to disc defects alone.

Another possibility is that GlActin helps maintain the structure of the disc, consistent

258 with its role in maintaining cell and organelle shape in other organisms [19,22]. The unusual

259 stability of disc microtubules can be at least partially attributed to certain DAPs $[8,15,17]$, which

260 lock the microtubules into place, preventing their turnover. GlActin interacts with at least one of

261 these DAPs, GL50803_5188 [18], and could be working in conjunction with it to stabilize the

262 disc microtubules themselves. Another explanation is that GlActin works to stabilize one of the

263 non-microtubule components of the ventral disc. The microtubules of the disc are overlaid by the

264 giardin-composed microribbons [54], which are connected by crossbridges [13,55]. Since the

265 spiral shape is often maintained, but unwound, in GlActin-depleted cells (Figure 1, Figure S2), it

266 may be that GlActin contributes to establishing and/or maintaining disc overlap, as the overlap

267 zone also functions as the anterior gate of the ventral disc.

268 A previous study from our lab identified eight $G l$ Actin interactors which localize to the

269 ventral disc, including DAAP1 [18]; here we confirmed complex formation between GlActin and

270 DAAP1 through co-immunoprecipitation (Figure 2). We did not detect co-localization between

271 DAAP1 and GlActin in interphase cells, but present evidence that indicates co-localization

272 during mitosis when new discs are assembled (Figure 2). Polymerized GlActin may be enriched 
273 in the ventral disc at these stages, but detection may be obscured due to technical limitations.

274 Unfortunately, use of the anti-GlActin antibody does not differentiate between filaments and

275 pools of monomeric GlActin which likely obscures some filaments. Currently, there are no

276 methods to specifically detect F-GlActin, as Rhodamine-Phalloidin does not bind to GlActin

277 filaments [22]. Actin in Toxoplasma gondii was believed to be primarily monomeric and only

278 capable of forming short filaments [56,57]. However, expression of an anti-actin nanobody

279 revealed a previously unseen complex network of F-actin [58]. Poor detection of GlActin using

280 the anti-GlActin antibody could also be due to steric hindrance. Actin-binding proteins could

281 sterically block access of anti-GlActin antibodies to disc-localized GlActin, similar to low anti-

282 tubulin antibody staining compared to our ability to see microtubules of the disc with

283 mNeonGreen-Tubulin [27]. Another possibility is that actin only transiently associates with the

284 disc for specific conformational changes which would be challenging to capture in fixed cells. A

285 live marker specific for GlActin is needed to determine the extent of actin association with

286 conformational dynamics of the ventral disc including disc doming, bare area protrusion and disc

287 flexion as seen in Movie S1.

288 Similar to other disc-associated proteins [44], DAAP1's localization to the disc is stable,

289 as we did not see any recovery of this protein for 12 minutes after photobleaching (Figure 4).

290 While DAAP1 was previously identified as a potential disc interactor, it was not found in high

291 enough abundance in the detergent-extracted disc proteome to qualify for further study as a disc-

292 associated protein [14]. These results possibly indicating that this protein is a peripheral

293 component of the disc, which would be expected in order for it to engage with a dynamic subset

294 of GlActin.

295 Using CRISPR-interference, we depleted DAAP1 from cells, and found a mild defect in 
attachment, but no obvious impact on disc morphology (Figures 5-7). While a DAAP1 knockout would give us better insight into how DAAP1 loss affects the disc, the ability to readily knockout genes of interest remains under development. CRISPRi and Morpholino knockdown both have variable penetrance, and thus the level of depletion fluctuates among cells, and we observed normal discs even in cells with very little DAAP1 fluorescence (Figure 5). In contrast, depletion

301 of median body protein with morpholinos results in broken discs [12]. Although an inability to

302 attach can be attributed to disc defects [12,30], the depletion of gamma-giardin, another disc-

303 localized protein that interacts with GlActin [18], resulted in malformed discs with normal

304 attachment [59]. These findings indicate that some disc proteins may be involved in maintaining

305 the structural integrity of the disc, while others are involved in controlling conformational

306 changes of the disc required for modulating attachment. Our data is consistent with DAAP1

307 being in the latter category. [12]

308 The possibility that some disc proteins contribute to attachment but not structure may 309 also explain the disparity between the severity of attachment defects in GlActin-depleted cells 310 and DAAP1-depleted cells. Since many of the discs in GlActin-depleted cells were unwound or 311 misshapen, this suggests roles in building the disc or collaboration with DAPs that maintain the

312 disc structure. However, since over $25 \%$ of our unattached GlActin-depleted cells had apparently 313 normal discs, the attachment defect cannot be attributed to disc defects alone. Our previous study 314 identified eight other putative disc-localized F-GlActin interactors which could also contribute to 315 attachment and/or disc morphology [18].

316 An additional explanation for the severity of attachment defects in GlActin-depleted cells

317 is due to its involvements in supplemental mechanisms of attachment. GlActin has been

318 demonstrated to function in building the ventrolateral flange, Giardia's membrane lamella which 
319 also contributes to attachment [60,61]. Further, the marginal plate, a rigid structure associated

320 with the anterior axonemes, is also hypothesized to be involved in attachment $[11,32]$. GlActin is

321 stably enriched in this structure [22,62] and we have described six interactors which localize

322 there as well [18]. Given GlActin's involvement in all three structures hypothesized to augment

323 attachment, depletion of GlActin likely has multivariant effects on attachment, contributing to a

324 more severe phenotype.

325 The biology of parasites is often unlike anything seen in other organisms, shaped by the

326 unusual environments in which they live. Giardia's ventral disc exemplifies parasitic innovation

327 and makes this Giardia specific structure a target for drug development. Since most DAPs lack

328 homologs, they are in theory potential drug targets; however, the lack of active sites reduces their

329 potential [63]. Further understanding of the mechanisms of attachment and its regulation will

330 increase the viability of developing drugs that could specifically function through regulating

331 attachment. Actin, however, is a druggable protein and conventional actin drugs do not bind to

332 GlActin or inhibit its function, rendering it an appealing therapeutic target.

\section{Materials and Methods}

\section{Parasite Strain and Growth Conditions}

337 G. lamblia strain WB clone 6 (ATCC 50803; American Type Culture Collection) was cultured as 338 described previously [22]. 
341 All constructs in this study were C-terminal fusions, made using Gibson reactions with linearized

342 vectors and PCR products [64]. See Supplemental Table 3 for primer sequences and workflow.

\section{Live Cell Imaging}

345 Cells were chilled with ice for 15 minutes to detach from the culture tube and then placed into an

346 Attofluor cell chamber (Molecular Probes) and incubated in a GasPak EZ anaerobic pouch (BD)

347 or a Tri-gas incubator (Panasonic) set to $2.5 \% \mathrm{O} 2,5 \% \mathrm{CO} 2$ for 90 minutes at $37^{\circ} \mathrm{C}$. Cells were

348 then washed four times with HEPES-buffered saline (HBS: $137 \mathrm{mM} \mathrm{NaCl}, 5 \mathrm{mM} \mathrm{KCl}, 0.91 \mathrm{mM}$

349 Na2HpO4-heptahydrate, 5.55mM Glucose, 20mM HEPES, pH7). Live cell imaging was

350 performed on a DeltaVision Elite microscope (GE) equipped with DIC optics, using a $100 \times 1.4$

351 NA or $60 \times 1.42$ NA objective, and a sCMOS 5.4 PCle air-cooled camera (PCO-TECH).

\section{Coimmunoprecipitation}

354 Cell cultures of $500 \mathrm{~mL}$ each of Giardia wildtype and DAAP1-3xHA were grown for 3 days,

355 then iced for 2 hours to detach, and spun for $1500 \mathrm{xg}$ at $4^{\circ} \mathrm{C}$ for 20 minutes. Cells were then

356 washed twice in $1 \mathrm{X}$ HBS with $2 \mathrm{X}$ HALT protease inhibitors and $10 \mu \mathrm{M}$ chymostatin, $1 \mu \mathrm{M}$

357 leupeptin, and $1 \mu \mathrm{M}$ E64. Each pellet was resuspended to a final volume of $1.2 \mathrm{~mL}$ and $100 \mathrm{mM}$

358 DSP in DMSO was added to a final concentration of $1 \mathrm{mM}$ and incubated at room temperature

359 for 30 minutes. The reaction was quenched for 15 minutes with an addition of Tris $\mathrm{pH} 7.4$ final

360 concentration $20 \mathrm{mM}$. Cells were then pelleted by spinning for 7 minutes at $700 \mathrm{xg}$ and

361 resuspended in $350 \mu \mathrm{L}$ lysis buffer $(80 \mathrm{mM} \mathrm{KCl}, 10 \mathrm{mM}$ imidazole, $1 \mathrm{mM} \mathrm{MgCl} 2,1 \mathrm{mM}$

362 EGTA, 5\% Glycerol, 20 mM HEPES, 0.2 mM, CaCl2, 10 mM ATP, 0.1\% Triton X-100, 500

$363 \mathrm{mM} \mathrm{NaCl}, \mathrm{pH} 7.2,2 \mathrm{XHALT}$ protease inhibitors and $10 \mu \mathrm{M}$ chymostatin, $1 \mu \mathrm{M}$ leupeptin, and 1 
$364 \mu \mathrm{M}$ E64). Cells were then lysed by sonication and cleared with a 10 minute spin at 10,000xg. A

365 volume of $17.5 \mu \mathrm{L}$ of equilibrated EZview Red Anti-HA Affinity gel (Sigma) was added to each

366 tube of lysate, then incubated at $4{ }^{\circ} \mathrm{C}$ with end-over-end mixing for 1 hour. Beads were then spun

367 at $8,200 x g$ for 30 seconds and the supernatant was discarded, followed by a total of three washes

368 with $750 \mu \mathrm{L}$ wash buffer $(80 \mathrm{mM} \mathrm{KCl}, 10 \mathrm{mM}$ imidazole, $1 \mathrm{mM} \mathrm{MgCl} 2,1 \mathrm{mM}$ EGTA, 5\%

369 Glycerol, 20 mM HEPES, 0.2 mM CaCl2, $10 \mathrm{mM}$ ATP, 0.5\% Tween, $500 \mathrm{mM} \mathrm{NaCl,} \mathrm{pH} \mathrm{7.2).}$

370 Each wash consisted of end-over-end rotation for 5 minutes followed by a 30 second spin at

$3718,200 \mathrm{x}$ g. Protein was then incubated with $50 \mu \mathrm{L}$ of $8 \mathrm{M}$ Urea at RT for 20 minutes to elute. The

372 beads were pelleted and then sample buffer was added to the supernatant, the sample was boiled

373 for 5 mins at $98^{\circ} \mathrm{C}$, and run on a $12 \%$ SDS-PAGE gel, followed by western blot protocol

374 described previously [22].

375

\section{Immunofluorescence Microscopy}

377 Fixation and imaging were performed as described in previous work [65], with the addition of a

378 JaneliaFluor 646 HaloTag ligand (Promega, GA1120) or JaneliaFluor 549 HaloTag ligand

379 (Promega, GA1110) at 1:100 in the second immunostaining step. Image analysis was performed

380 in FIJI [66]. DAAP1 intensity was measured by generating a circular region of interest

381 surrounding the ventral groove and measuring fluorescence intensity at the brightest point in

382 each image stack.

\section{Morpholino Knockdown}

385 Morpholino knockdown was performed as described previously [67]. Cells were lysed and run

386 on a $10 \%$ SDS-PAGE gel, followed by western blot protocol as described previously [18,22]. 
387 For each of three biological replicates, samples were divided equally into three lanes and

388 intensity of each lane measured using FIJI and averaged. Cell counts were performed with a

389 MoxiZ coulter counter to ensure the same number of cells were included in each sample. For

390 morpholino sequences, see Supplemental Table 3.

393 Culture Tube Attachment Assay

394 GlActin: Cells were treated with either a standard control or anti-GlActin morpholino and

395 allowed to recover for 24 hours in a total volume of $13 \mathrm{~mL}$ of TYDK media at $37^{\circ} \mathrm{C}$. At 24

396 hours, each culture tube was inverted six times; detached cells in media were decanted and

397 counted with a MoxiZ coulter counter (Orflo), then replaced with $13 \mathrm{~mL}$ ice cold media. Culture

398 tubes were placed on ice for 30 minutes to detach the remaining cells, after which these were

399 also counted. Cells were then imaged live or fixed as described previously [27]. Three

400 independent replicates of each experimental and control were analyzed. DAAP1 assays were

401 performed similarly, except knockdown was accomplished with CRISPRi rather than

402 morpholinos (see below).

404 Assessment for Live/Dead Cells

405 Stock solutions of dye were created by dissolving $5 \mathrm{mg}$ fluorescein diacetate (Sigma-Aldrich, F-

406 7378) in $1 \mathrm{ml}$ acetone and $2 \mathrm{mg}$ propidium iodide (Sigma-Aldrich, P4170) in $1 \mathrm{ml} \mathrm{HBS.} \mathrm{A} \mathrm{2X}$

407 stain solution was prepared by diluting the stock solutions of fluorescein diacetate and propidium

408 iodide by 1:100 in $1 \mathrm{X} \mathrm{HBS}$. Cells were pelleted by centrifugation at $500 \mathrm{x} \mathrm{g}$ and resuspended in 
$1 \mathrm{~mL} 1 \mathrm{X}$ HBS. $1 \mathrm{~mL}$ of $2 \mathrm{x}$ stain solution was then added to the cell suspension, washed twice in

410 1X HBS by centrifugation and resuspended in $1 \mathrm{X}$ HBS for imaging.

\section{Fluorescence Recovery after Photobleaching.}

413 FRAP was performed on DAAP1-mNeonGreen in the ventral disc to measure protein turnover.

414 Cells were chilled with ice for 20 minutes to detach from the culture tube and then placed into an

415 Attofluor cell chamber (Molecular Probes) and incubated in a $\mathrm{O}_{2} / \mathrm{CO}_{2}$ incubator (Panasonic) for

$4161-2$ hours at $37^{\circ} \mathrm{C}$. Media was replaced with $37^{\circ} \mathrm{C} 1 \mathrm{X}$ HBS before imaging. All experiments

417 were conducted using a FRAP-enabled DeltaVision Spectris with $405 \mathrm{~nm}$ solid-state laser, 100\%

418 laser power, $50 \mathrm{~mW}$ laser, and $25 \mathrm{~ms}$ stationary pulse. Three images were taken until the bleach

419 event for 0.5 second intervals, followed by image acquisition every $10 \mathrm{sec}$ for 10 minutes.

420 Normalized mNeonGreen fluorescence recovery was calculated by subtracting the background

421 noise from the ROI intensity measurement; to normalize for photobleaching due to imaging, this

422 measurement was then divided by a fluorescent control ROI intensity measurement with the

423 background noise subtracted as well.

\section{CRISPR Interference Knockdown}

426 Constructs were designed as described previously [68]. For primer design and workflow, see

427 Supplemental Table 3. Cells containing an integrated C-terminally mNeonGreen-tagged DAAP1

428 were transfected with a dead Cas9 vector which contained either a non-specific small guide RNA

429 (dCas9-CTRL) or a small guide RNA targeting base pairs 392 through 411 of the coding region

430 of DAAP1 (dCas9+sgRNA392-411). Knockdown efficiency was measured using a Tecan Spark

431 plate reader. Cells were pelleted and washed with $1 \mathrm{X}$ PBS and then resuspended in $1 \mathrm{X}$ PBS. An 
432 equal number of dCas9-CTRL or dCas9+sgRNA392-411cells were loaded into Tecan black flat

433 96-well plates and the volume was adjusted to a total of $150 \mu \mathrm{L}$. Three measurements per sample

434 were averaged and three independent transformations were averaged for total knockdown

435 efficiency, normalized to the control and blanked with $1 \mathrm{X}$ PBS.

\section{Shear Force Attachment Assay}

438 Microfluidic devices were fabricated using a silicon master, which was created using deep

439 reactive ion etching. The silicon master contained a raised channel that had a rectangular cross-

440 sectional area, with a length of $1 \mathrm{~cm}$, a width of $1 \mathrm{~mm}$, and a height of $115 \mu \mathrm{m}$. A

441 polydimethylsiloxane (PDMS) (Sylgard 184, Dow Corning) mold was made using a 10:1 base to

442 curing agent ratio, which was mixed for 5 minutes, degassed for 20 minutes, poured over the

443 master, and placed in an oven for 10 minutes at $110^{\circ} \mathrm{C}$ to cure. The mold was peeled away from

444 the silicon master and holes were punched for the inlet and outlet of the channel. Afterwards,

445 inlet and outlet ports were created using a custom aluminum mold with pegs to insert the silicone

446 tubing (0.040 inch ID/ 0.085 inch OD, HelixMark). Degassed 10:1 PDMS was poured into the

447 preheated aluminum mold and cured at $110{ }^{\circ} \mathrm{C}$ for 1 hour. The inlet and outlet ports were aligned

448 with holes on the top face of the microfluidic device and stuck together using uncured PDMS

449 and 5 minutes of oven heat. Finally, the bottom face of the microfluidic device and a clean glass

450 slide were plasma treated for 10 seconds and aligned together to create a water-tight seal

451 between the two layers.

452 Control dCas9 or DAAP1 targeting dCas9+sgRNA392-411 trophozoites were chilled for 20

453 minutes on ice and then loaded into microfluidic devices placed in a GasPak EZ anaerobic pouch

454 (BD Scientific) at $37 \square^{\circ} \mathrm{C}$ for $1 \mathrm{~h}$ to allow re-attachment. Growth media was drawn into a 
455 disposable syringe (BD Scientific) and then loaded onto a syringe pump (Harvard Apparatus).

456 For experiments, the flow rate was set to $20 \mu 1 / \mathrm{min}$ for $30 \square \mathrm{s}$ to clear swimming trophozoites and

457 then ramped to $100 \mu 1 /$ min over $5 \mathrm{~s}$ and challenged for $60 \mathrm{~s}$. The challenge assays were recorded

458 at 2 FPS using a Nikon Eclipse Ti microscope with a 40X objective, using phase illumination,

459 Clara DR-1357 CCD camera (Andor), and a live-cell incubation chamber (In Vivo Scientific,

460 Inc) to maintain a temperature of $37 \square^{\circ} \mathrm{C}$. Trophozoite mean speed was quantified starting at $35 \mathrm{~s}$

461 using the TrackMate ImageJ plugin via manual tracking over the first 10 seconds of $100 \mu \mathrm{L} / \mathrm{min}$

462 flow [31].

463 TIRF Microscopy

464 Cells were prepared for live imaging as described above, with the addition of CellMask ${ }^{\mathrm{TM}}$

465 Orange Plasma membrane Stain (ThermoFisher) according to manufacturer's instructions after

466 media replacement with $1 \mathrm{X}$ HBS. Cells were imaged in a chamber with $2 \% \mathrm{CO} 2$ and $5 \% \mathrm{O} 2$

467 with a DeltaVision OMX (GE) using 60X TIRF objective. Images were taken from randomly

468 selected fields of view. Each dish was imaged for a maximum of 30 minutes to minimize stress

469 on the cells. Three dishes from two independent experiments were used for each condition.

\section{Live Imaging with Microspheres}

472 Cells expressing DAAP1-mNeonGreen were transfected with a plasmid containing Halo-tagged

473 delta-giardin and either dCas9 control or dCas9+sgRNA392-411 to deplete DAAP1. Cells were

474 grown in parallel and upon confluency were chilled with ice for 15 minutes to detach from the

475 culture tube and then placed into an Attofluor cell chamber (Molecular Probes), then incubated

476 in a GasPak EZ anaerobic pouch (BD) or a Tri-gas incubator (Panasonic) set to 2.5\% O2, 5\%

$477 \mathrm{CO}_{2}$ for 90 minutes at $37^{\circ} \mathrm{C} .646$ HaloTag ligand (Promega, GA1120) was added to cells 45 
478 minutes after incubation at 1:1000 concentration, incubated for 15 minutes, and then replaced

479 with TYDK for 30 minutes prior to imaging. $2.5 \mu \mathrm{L}$ of fluorescent microspheres $(0.2 \mu \mathrm{m}$,

480 Polysciences Fluoresbrite® YO Carboxylate Microspheres catalog number 19391) were added to

$481 \quad 0.5 \mathrm{~mL} 1 \mathrm{xHBS}$ and sonicated for 10 minutes using a bath sonicator to disrupt aggregates. This

482 diluted solution was then added to cells at a 1:10 ratio to each chamber $(30 \mu \mathrm{L}$ diluted bead

483 solution in $300 \mu \mathrm{L}$ cells). Images of single focal planes in which the disc was visible were taken

484 every 1 second for 15 seconds for each condition. Cells with beads which were collected under

485 their ventral disc and cells with no beads were counted. Cells which detached or moved were

486 excluded from analysis. Live cell imaging was performed on a DeltaVision Elite microscope

487 (GE) equipped with DIC optics, using a $60 \times 1.42$ NA objective, and a sCMOS 5.4 PCle air-

488 cooled camera (PCO-TECH).

\section{Acknowledgements}

491 We thank Kelly Hennessey, Kelli Hvorecny, Han-wei Shih, Elizabeth Thomas, Barbara

492 Wakimoto, Susan Parkhurst and Germain Alas for manuscript editing. We thank Pang Chan for

493 assistance with TIRF microscopy at the Biology Imaging Facility.

495 This material is based upon work supported by the National Science Foundation Graduate

496 Research Fellowship under Grant No. DGE-1762114 to MSO. Funding for the OMX was

497 provided by grant proposal S10 OD021490. Research reported in this publication was supported

498 by the National Heart, Lung, And Blood Institute of the National Institutes of Health under

499 Award Number F31HL156697. The content is solely the responsibility of the authors and does

500 not necessarily represent the official views of the National Institutes of Health." 


\section{References}

1. Lane S, Lloyd D. Current Trends in Research into the Waterborne Parasite Giardia. Critical Reviews in Microbiology. 2002;28. doi:10.1080/1040-840291046713

2. Savioli L, Smith H, Thompson A. Giardia and Cryptosporidium join the 'Neglected Diseases Initiative.' Trends in Parasitology. 2006;22. doi:10.1016/j.pt.2006.02.015

3. Adam RD. Biology of Giardia lamblia. Clinical Microbiology Reviews. 2001;14. doi:10.1128/CMR.14.3.447-475.2001

4. Dawson SC. An insider's guide to the microtubule cytoskeleton of Giardia. Cellular Microbiology. 2010;12. doi:10.1111/j.1462-5822.2010.01458.x

5. Schwartz CL, Heumann JM, Dawson SC, Hoenger A. A Detailed, Hierarchical Study of Giardia lamblia's Ventral Disc Reveals Novel Microtubule-Associated Protein Complexes. PLoS ONE. 2012;7. doi:10.1371/journal.pone.0043783

6. Elmendorf HG, Dawson SC, McCaffery JM. The cytoskeleton of Giardia lamblia. International Journal for Parasitology. 2003;33. doi:10.1016/S0020-7519(02)00228-X

7. Nosala C, Dawson SC. The Critical Role of the Cytoskeleton in the Pathogenesis of Giardia. Current Clinical Microbiology Reports. 2015;2. doi:10.1007/s40588-015-0026-y

8. Nosala C, Dawson SC. The ventral disc is a flexible microtubule organelle that depends on domed ultrastructure for functional attachment of Giardia lamblia. bioRxiv. bioRxiv; 2017. doi:10.1101/213421

9. Nosala C, Hagen KD, Dawson SC. 'Disc-o-Fever': Getting Down with Giardia's Groovy Microtubule Organelle. Trends in Cell Biology. 2018;28. doi:10.1016/j.tcb.2017.10.007

10. Lenaghan SC, Davis CA, Henson WR, Zhang Z, Zhang M. High-speed microscopic imaging of flagella motility and swimming in Giardia lamblia trophozoites. Proceedings of the National Academy of Sciences. 2011;108: E550-E558. doi:10.1073/pnas.1106904108

11. Hagen KD, McInally SG, Hilton ND, Dawson SC. Microtubule organelles in Giardia. 2020. doi:10.1016/bs.apar.2019.11.001

12. Woessner DJ, Dawson SC. The Giardia Median Body Protein Is a Ventral Disc Protein That Is Critical for Maintaining a Domed Disc Conformation during Attachment. Eukaryotic Cell. 2012;11. doi:10.1128/EC.05262-11

13. Brown JR, Schwartz CL, Heumann JM, Dawson SC, Hoenger A. A detailed look at the cytoskeletal architecture of the Giardia lamblia ventral disc. Journal of Structural Biology. 2016;194. doi:10.1016/j.jsb.2016.01.011

14. House SA, Richter DJ, Pham JK, Dawson SC. Giardia Flagellar Motility Is Not Directly Required to Maintain Attachment to Surfaces. PLoS Pathogens. 2011;7. doi:10.1371/journal.ppat.1002167

15. Nosala C, Hagen KD, Hilton N, Chase TM, Jones K, Loudermilk R, et al. Disc-associated proteins mediate the unusual hyperstability of the ventral disc in Giardia lamblia. Journal 
16. Hagen KD, Hirakawa MP, House SA, Schwartz CL, Pham JK, Cipriano MJ, et al. Novel Structural Components of the Ventral Disc and Lateral Crest in Giardia intestinalis. PLoS Neglected Tropical Diseases. 2011;5. doi:10.1371/journal.pntd.0001442

17. Nosala C, Hagen KD, Dawson SC. 'Disc-o-Fever': Getting Down with Giardia's Groovy Microtubule Organelle. Trends in Cell Biology. 2018;28. doi:10.1016/j.tcb.2017.10.007

18. Steele-Ogus MC, Johnson R, MacCoss M, Paredez AR. Identification of Actin Filament Interactors in Giardia lamblia. [cited 7 Apr 2021]. doi:https://doi.org/10.1128/Spectrum.00558-21

19. Pollard TD. Actin and Actin-Binding Proteins. Cold Spring Harbor Perspectives in Biology. 2016;8. doi:10.1101/cshperspect.a018226

20. Feely DE, Schollmeyer J v., Erlandsen SL. Giardia spp.: Distribution of contractile proteins in the attachment organelle. Experimental Parasitology. 1982;53.

doi:10.1016/0014-4894(82)90100-X

21. Drouin G, de Sá MM, Zuker M. The Giardia lamblia actin gene and the phylogeny of eukaryotes. Journal of Molecular Evolution. 1995;41. doi:10.1007/BF00173163

22. Paredez AR, Assaf ZJ, Sept D, Timofejeva L, Dawson SC, Wang C-JR, et al. An actin cytoskeleton with evolutionarily conserved functions in the absence of canonical actinbinding proteins. Proceedings of the National Academy of Sciences. 2011;108. doi:10.1073/pnas.1018593108

23. Morrison HG, McArthur AG, Gillin FD, Aley SB, Adam RD, Olsen GJ, et al. Genomic Minimalism in the Early Diverging Intestinal Parasite Giardia lamblia. Science. 2007;317. doi:10.1126/science. 1143837

24. Aurrecoechea C, Brestelli J, Brunk BP, Carlton JM, Dommer J, Fischer S, et al. GiardiaDB and TrichDB: integrated genomic resources for the eukaryotic protist pathogens Giardia lamblia and Trichomonas vaginalis. Nucleic Acids Research. 2009;37. doi:10.1093/nar/gkn631

25. Schneider CA, Rasband WS, Eliceiri KW. NIH Image to ImageJ: 25 years of image analysis. Nature Methods. 2012;9. doi:10.1038/nmeth.2089

26. BOLTE S, CORDELIÈRES FP. A guided tour into subcellular colocalization analysis in light microscopy. Journal of Microscopy. 2006;224. doi:10.1111/j.1365-

2818.2006.01706.x

27. Hardin WR, Li R, Xu J, Shelton AM, Alas GCM, Minin VN, et al. Myosin-independent cytokinesis in Giardia utilizes flagella to coordinate force generation and direct membrane trafficking. Proceedings of the National Academy of Sciences. 2017;114.

doi:10.1073/pnas.1705096114

28. Tůmová P, Kulda J, Nohýnková E. Cell division ofGiardia intestinalis: Assembly and disassembly of the adhesive disc, and the cytokinesis. Cell Motility and the Cytoskeleton. 2007;64. doi:10.1002/cm.20183

29. Nohýnková E, Tu $\square$ mová P, Kulda J. Cell Division of Giardia intestinalis: Flagellar Developmental Cycle Involves Transformation and Exchange of Flagella between Mastigonts of a Diplomonad Cell. Eukaryotic Cell. 2006;5. doi:10.1128/EC.5.4.753761.2006

30. McInally SG, Hagen KD, Nosala C, Williams J, Nguyen K, Booker J, et al. Robust and stable transcriptional repression in Giardia using CRISPRi. Molecular Biology of the Cell. 2019;30. doi:10.1091/mbc.E18-09-0605 
31. Tinevez J-Y, Perry N, Schindelin J, Hoopes GM, Reynolds GD, Laplantine E, et al. TrackMate: An open and extensible platform for single-particle tracking. Methods. 2017;115. doi:10.1016/j.ymeth.2016.09.016

32. Dawson SC, Paredez AR. Alternative cytoskeletal landscapes: cytoskeletal novelty and evolution in basal excavate protists. Current Opinion in Cell Biology. 2013;25. doi:10.1016/j.ceb.2012.11.005

33. Avasthi P, Onishi M, Karpiak J, Yamamoto R, Mackinder L, Jonikas MC, et al. Actin Is Required for IFT Regulation in Chlamydomonas reinhardtii. Current Biology. 2014;24. doi:10.1016/j.cub.2014.07.038

34. Jack B, Mueller DM, Fee AC, Tetlow AL, Avasthi P. Partially Redundant Actin Genes in Chlamydomonas Control Transition Zone Organization and Flagellum-Directed Traffic. Cell Reports. 2019;27. doi:10.1016/j.celrep.2019.04.087

35. Gervasi MG, Xu X, Carbajal-Gonzalez B, Buffone MG, Visconti PE, Krapf D. The actin cytoskeleton of the mouse sperm flagellum is organized in a helical structure. Journal of Cell Science. 2018;131. doi:10.1242/jcs.215897

36. Yanagisawa H, Kamiya R. Association between Actin and Light Chains in Chlamydomonas Flagellar Inner-Arm Dyneins. Biochemical and Biophysical Research Communications. 2001;288. doi:10.1006/bbrc.2001.5776

37. Kato-Minoura T, Hirono M, Kamiya R. Chlamydomonas Inner-Arm Dynein Mutant, ida5, Has a Mutation in an Actin-encoding Gene. Journal of Cell Biology. 1997;137. doi:10.1083/jcb.137.3.649

38. Gui M, Ma M, Sze-Tu E, Wang X, Koh F, Zhong ED, et al. Structures of radial spokes and associated complexes important for ciliary motility. Nature Structural \& Molecular Biology. 2021;28. doi:10.1038/s41594-020-00530-0

39. Wieczorek M, Urnavicius L, Ti S-C, Molloy KR, Chait BT, Kapoor TM. Asymmetric Molecular Architecture of the Human $\gamma$-Tubulin Ring Complex. Cell. 2020;180. doi:10.1016/j.cell.2019.12.007

40. Sugioka K, Bowerman B. Combinatorial Contact Cues Specify Cell Division Orientation by Directing Cortical Myosin Flows. Developmental Cell. 2018;46. doi:10.1016/j.devcel.2018.06.020

41. Scarpa E, Finet C, Blanchard GB, Sanson B. Actomyosin-Driven Tension at Compartmental Boundaries Orients Cell Division Independently of Cell Geometry In Vivo. Developmental Cell. 2018;47. doi:10.1016/j.devcel.2018.10.029

42. Kita AM, Swider ZT, Erofeev I, Halloran MC, Goryachev AB, Bement WM. Spindle-Factin interactions in mitotic spindles in an intact vertebrate epithelium. Molecular Biology of the Cell. 2019;30. doi:10.1091/mbc.E19-02-0126

43. Sugizaki A, Sato K, Chiba K, Saito K, Kawagishi M, Tomabechi Y, et al. POLArIS, a versatile probe for molecular orientation, revealed actin filaments associated with microtubule asters in early embryos. Proceedings of the National Academy of Sciences. 2021;118. doi:10.1073/pnas.2019071118

44. Tosetti N, Dos N, Pacheco S, Soldati-Favre D, Jacot D. Three F-actin assembly centers regulate organelle inheritance, cell-cell communication and motility in Toxoplasma gondii. 2019. doi:10.7554/eLife.42669.001

45. Hu K, Roos DS, Murray JM. A novel polymer of tubulin forms the conoid of Toxoplasma gondii. Journal of Cell Biology. 2002;156. doi:10.1083/jcb.200112086 
632 46. Das S, Stortz JF, Meissner M, Periz J. The multiple functions of actin in apicomplexan parasites. Cellular Microbiology. 2021. doi:10.1111/cmi.13345

47. MONDRAGON R, FRIXIONE E. $\mathrm{Ca}^{2+}$-Dependence of Conoid Extrusion in Toxoplasma gondii Tachyzoites. Journal of Eukaryotic Microbiology. 1996;43. doi:10.1111/j.15507408.1996.tb04491.x

48. del Carmen MG, Mondragón M, González S, Mondragón R. Induction and regulation of conoid extrusion in Toxoplasma gondii. Cellular Microbiology. 2009;11. doi:10.1111/j.1462-5822.2009.01304.x Associated Motor MyoH Is Indispensable for Toxoplasma gondii Entry and Exit from Host Cells. PLOS Pathogens. 2016;12. doi:10.1371/journal.ppat.1005388

50. dos Santos Pacheco N, Tosetti N, Koreny L, Waller RF, Soldati-Favre D. Evolution, Composition, Assembly, and Function of the Conoid in Apicomplexa. Trends in Parasitology. 2020;36. doi:10.1016/j.pt.2020.05.001

51. Roman A-C, Garrido-Jimenez S, Diaz-Chamorro S, Centeno F, Carvajal-Gonzalez JM. Centriole Positioning: Not Just a Little Dot in the Cell. 2019. doi:10.1007/978-3-03023173-6_8

52. Antoniades I, Stylianou P, Skourides PA. Making the Connection: Ciliary Adhesion Complexes Anchor Basal Bodies to the Actin Cytoskeleton. Developmental Cell. 2014;28. doi:10.1016/j.devcel.2013.12.003

53. Halpern AR, Alas GCM, Chozinski TJ, Paredez AR, Vaughan JC. Hybrid Structured Illumination Expansion Microscopy Reveals Microbial Cytoskeleton Organization. ACS Nano. 2017;11. doi:10.1021/acsnano.7b07200

54. Holberton DV. Arrangement of subunits in microribbons from Giardia. Journal of Cell Science. 1981;47. doi:10.1242/jcs.47.1.167

55. Gadelha APR, Benchimol M, de Souza W. Helium ion microscopy and ultra-highresolution scanning electron microscopy analysis of membrane-extracted cells reveals novel characteristics of the cytoskeleton of Giardia intestinalis. Journal of Structural Biology. 2015;190. doi:10.1016/j.jsb.2015.04.017

56. Skillman KM, Ma CI, Fremont DH, Diraviyam K, Cooper JA, Sept D, et al. The unusual dynamics of parasite actin result from isodesmic polymerization. Nature Communications. 2013;4. doi:10.1038/ncomms3285

57. Angrisano F, Delves MJ, Sturm A, Mollard V, McFadden GI, Sinden RE, et al. A GFPActin reporter line to explore microfilament dynamics across the malaria parasite lifecycle. Molecular and Biochemical Parasitology. 2012;182. doi:10.1016/j.molbiopara.2011.11.008

58. Periz J, Whitelaw J, Harding C, Gras S, del Rosario Minina MI, Latorre-Barragan F, et al. Toxoplasma gondii F-actin forms an extensive filamentous network required for material exchange and parasite maturation. eLife. 2017;6. doi:10.7554/eLife.24119

59. Kim J, Park S-J. Role of gamma-giardin in ventral disc formation of Giardia lamblia. Parasites \& Vectors. 2019;12. doi:10.1186/s13071-019-3478-8

60. Hardin WR, M Alas GC, Taparia N, Thomas EB, Hvorecny KL, Halpern AR, et al. The Giardia lamellipodium-like ventrolateral flange supports attachment and rapid cytokinesis. doi:10.1101/2021.01.31.429041 
61. ERLANDSEN SL, RUSSO AP, TURNER JN. Evidence for Adhesive Activity of the Ventrolateral Flange in Giardia lamblia. The Journal of Eukaryotic Microbiology. 2004;51. doi:10.1111/j.1550-7408.2004.tb00165.x

62. Paredez AR, Nayeri A, Xu JW, Krtková J, Cande WZ. Identification of Obscure yet Conserved Actin-Associated Proteins in Giardia lamblia. Eukaryotic Cell. 2014;13.

63. Makley LN, Gestwicki JE. Expanding the Number of 'Druggable' Targets: Non-Enzymes and Protein-Protein Interactions. Chemical Biology \& Drug Design. 2013;81. doi:10.1111/cbdd.12066

64. Gibson DG, Young L, Chuang R-Y, Venter JC, Hutchison CA, Smith HO. Enzymatic assembly of DNA molecules up to several hundred kilobases. Nature Methods. 2009;6. doi:10.1038/nmeth.1318

65. Krtková J, Thomas EB, Alas GCM, Schraner EM, Behjatnia HR, Hehl AB, et al. Rac Regulates Giardia lamblia Encystation by Coordinating Cyst Wall Protein Trafficking and Secretion. mBio. 2016;7. doi:10.1128/mBio.01003-16

66. Schneider CA, Rasband WS, Eliceiri KW. NIH Image to ImageJ: 25 years of image analysis. Nature Methods. 2012;9. doi:10.1038/nmeth.2089

67. Krtková J, Paredez AR. Use of Translation Blocking Morpholinos for Gene Knockdown in Giardia lamblia. 2017. doi:10.1007/978-1-4939-6817-6_11

68. Hennessey KM, Alas GCM, Rogiers I, Li R, Merritt EA, Paredez AR. Nek8445, a protein kinase required for microtubule regulation and cytokinesis in Giardia lamblia. Molecular Biology of the Cell. 2020;31. doi:10.1091/mbc.E19-07-0406 
A

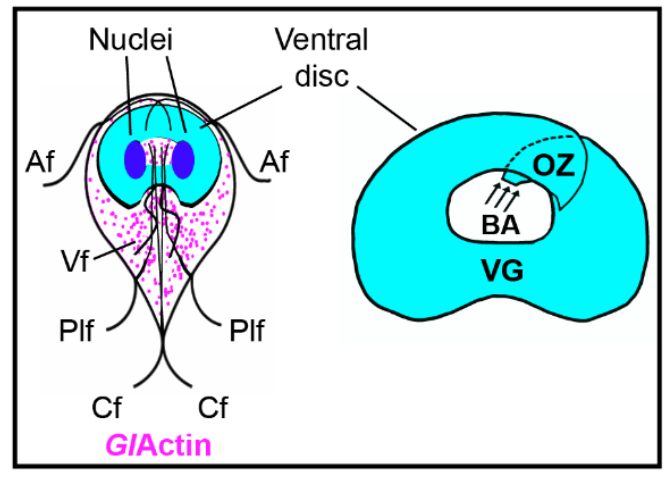

D

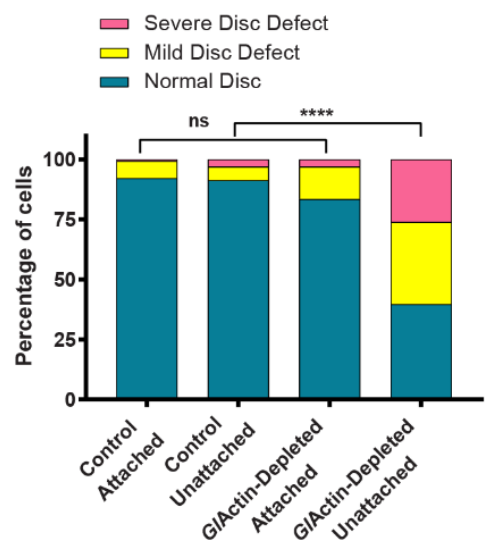

700

701

702

703

704

705

706

707

708
B

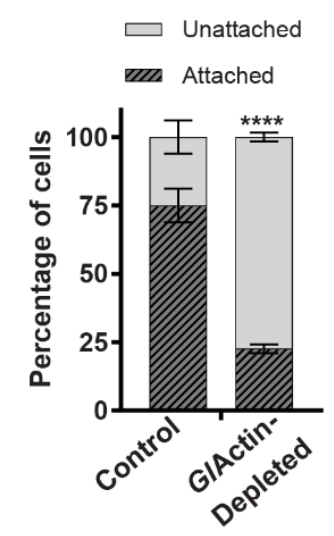

E
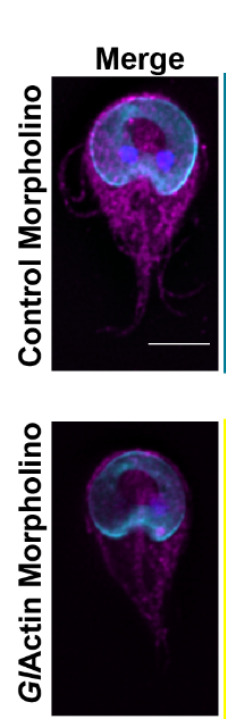

Attached

Delta-
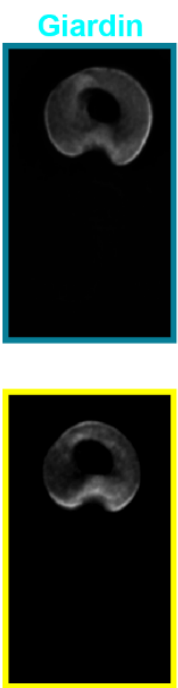

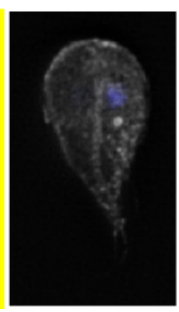

C

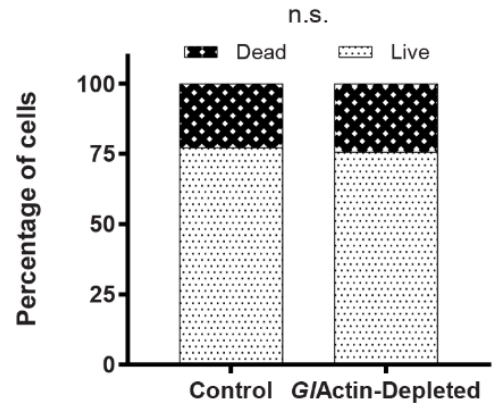

Unattached

Delta-
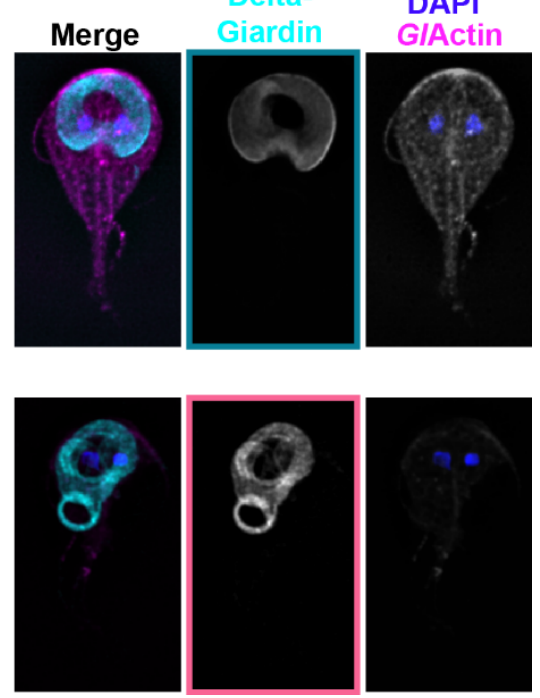

Figure 1: Depletion of GlActin affects attachment and ventral disc morphology

A) Left: Diagram of a Giardia trophozoite showing GlActin (magenta), disc marker delta-giardin (cyan), and DAPI/nuclei (blue). Anterior (Af), posteriolateral (Plf), ventral (Vf), and caudal flagella (Cf) are shown. Right: Enlarged diagram of ventral disc and areas: overlap zone (OZ), ventral groove (VG), and bare area (BA). Arrows indicate the origin of the microtubule sheet and orientation of the microtubule plus ends. B) Quantification of non-challenged attachment assays.

Attached and unattached cells were counted 24 hours after treatment with either a standard control or anti-GlActin morpholino. Graph is representative of an average of three replicates, 
709 mean \pm sem. For control, $74 \% \pm 6$ were attached and $25 \% \pm 6$ were detached. For GlActin-

710 depleted cells $23 \% \pm 2$ were attached and $77 \% \pm 2$ detached. Raw numbers and detailed statistics

711 reported in Supplemental Table 1. Each replicate was analyzed separately with a two-sided chi-

712 square test with Yates' correction, $\mathrm{P}<0.0001$ for each. C) Unattached cells from B were stained

713 with propidium iodide and fluorescein diacetate to distinguish dead from living cells

714 respectively. $\mathrm{N}=198$ control cells and 222 GlActin-depleted cells. There was no significant

715 difference between the two groups based on a two-sided Fisher's exact test $\mathrm{P}=0.7307$. D) Both

716 attached and unattached GlActin-depleted and control cells were fixed and immunostained for

717 delta-giardin to assess ventral disc morphology using fluorescence microscopy. $\mathrm{N}=126$ cells for

718 each condition. There was a significant difference in unattached cells based on a two-sided chi-

719 square test with Yates' correlation, $\mathrm{P}<0.0001$. No significant difference was detected in attached

720 cells based on the same test, $\mathrm{P}<0.0903$ E) Representative images of cells from $\mathrm{D}$, with examples

721 of normal discs (teal), mild defects (yellow), and severe defects (pink). Scale bar denotes $5 \mu \mathrm{m}$. 
A

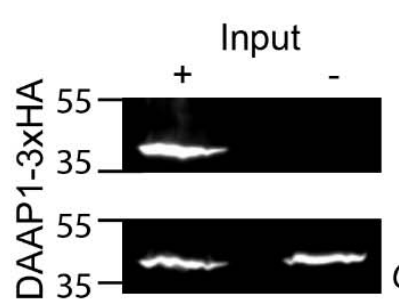

C
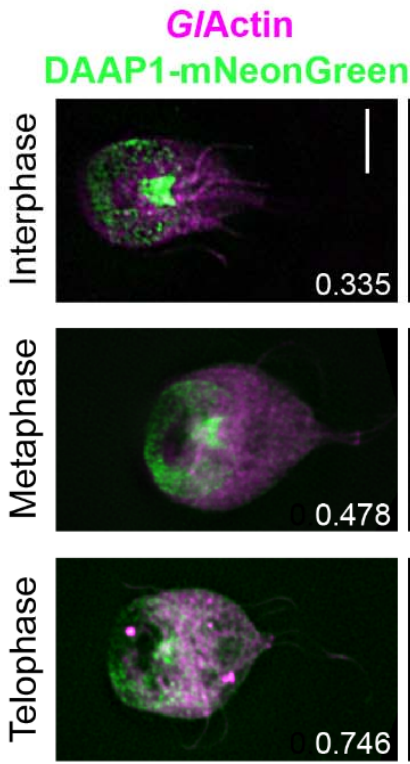

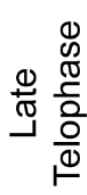

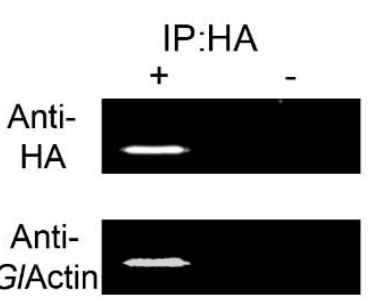

B

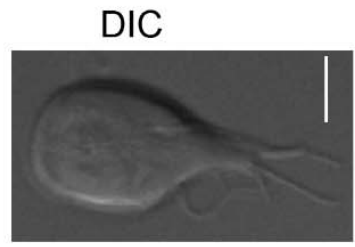

DAPI

\section{Tubulin}
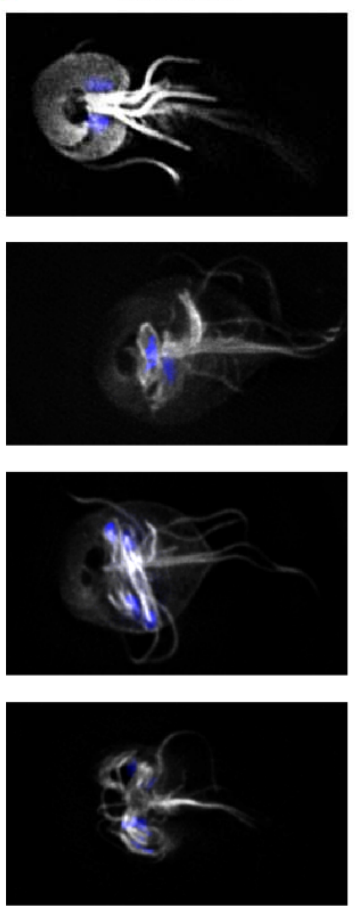
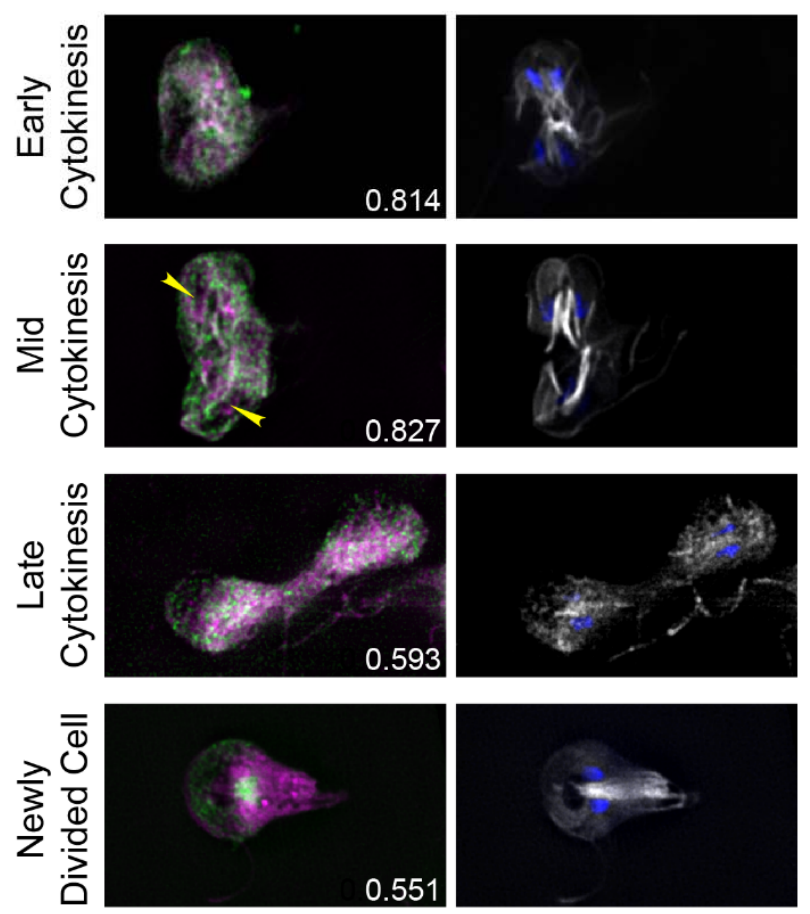

DAAP1mNeonGreen
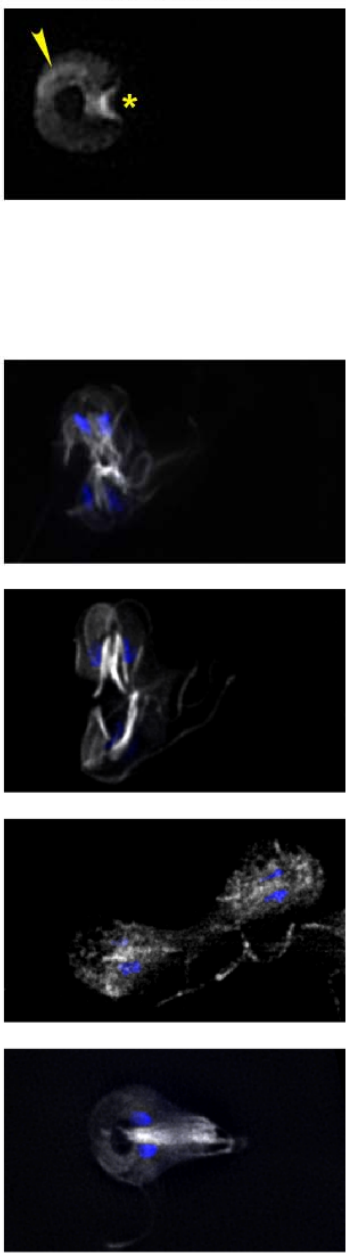

727 Figure 2: DAAP1 is a GlActin interactor and a ventral disc-associated protein

728 A) Immunoprecipitation from extracts of cells expressing DAAP1-3XHA and wild type cells,

729 followed by western blots probed with anti-GlActin and anti-HA antibodies, revealed interaction

730 between the two proteins. B) Image of DAAP1-mNeonGreen in a live cell. The fusion protein

731 localizes to the disc and is enriched in the ventral groove (asterisk) and overlap zone (arrow).

732 Scale bar denotes $5 \mu \mathrm{m}$. C) Immunofluorescence of GlActin (magenta), tubulin (cyan), DAAP1-

733 mNeonGreen (green), and DAPI/nuclei (blue) during the cell cycle. DAAP1-

734 mNeonGreenremains on the disc into telophase, is incorporated into the nascent discs by mid 
bioRxiv preprint doi: https://doi.org/10.1101/2021.08.06.455446; this version posted November 24,2021 . The copyright holder for this preprint (which was not certified by peer review) is the author/funder, who has granted bioRxiv a license to display the preprint in perpetuity. It is made available under aCC-BY-NC-ND 4.0 International license.

735 cytokinesis (see arrows), and localization is fully restored in newly divided cells. Pearson's

736 correlation coefficients using Costes randomization were calculated for colocalization between

737 DAAP1 and GlActin in each image, shown in the lower righthand corner. The Costes P-value

738 was 1 for all images. Scale bar denotes $5 \mu \mathrm{m}$.

739 
A
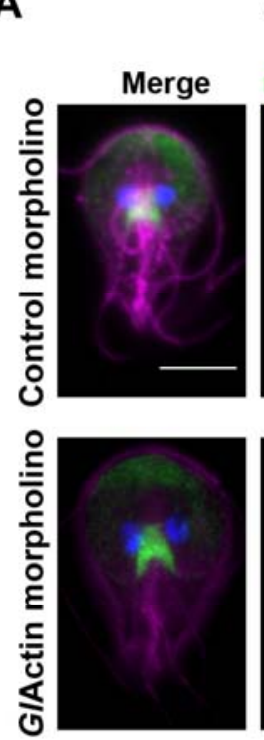

C
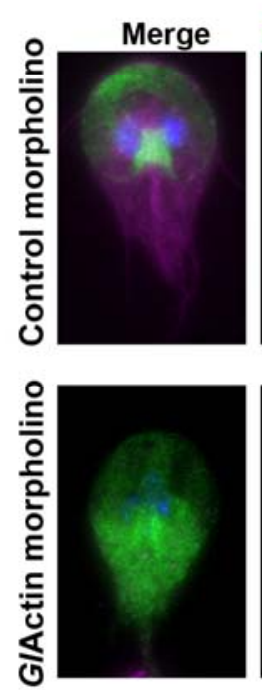

Attached

DAAP1-
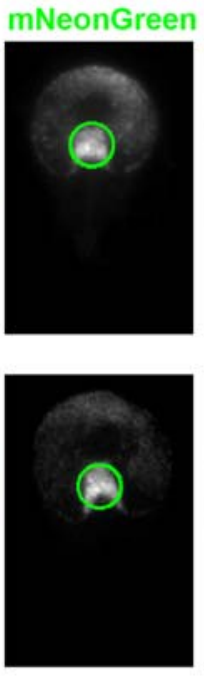

Unattached

DAAP1 -
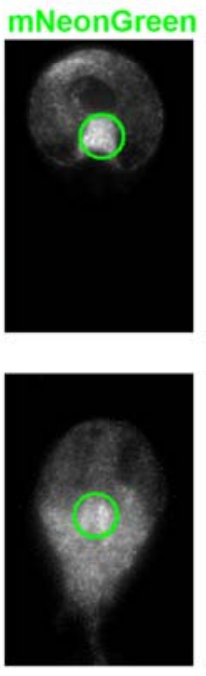

DAPI

GIActin
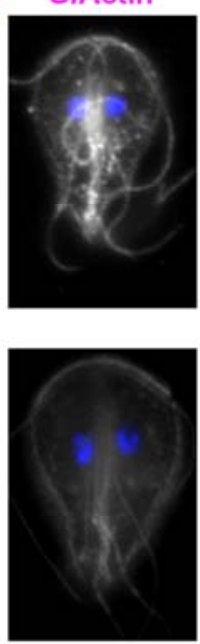

DAPI

GlActin
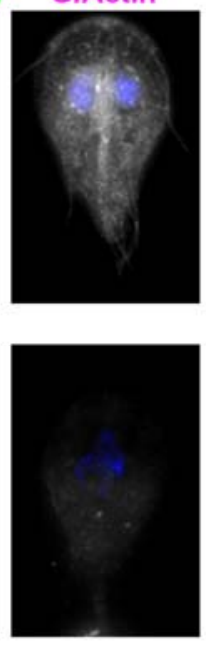

B
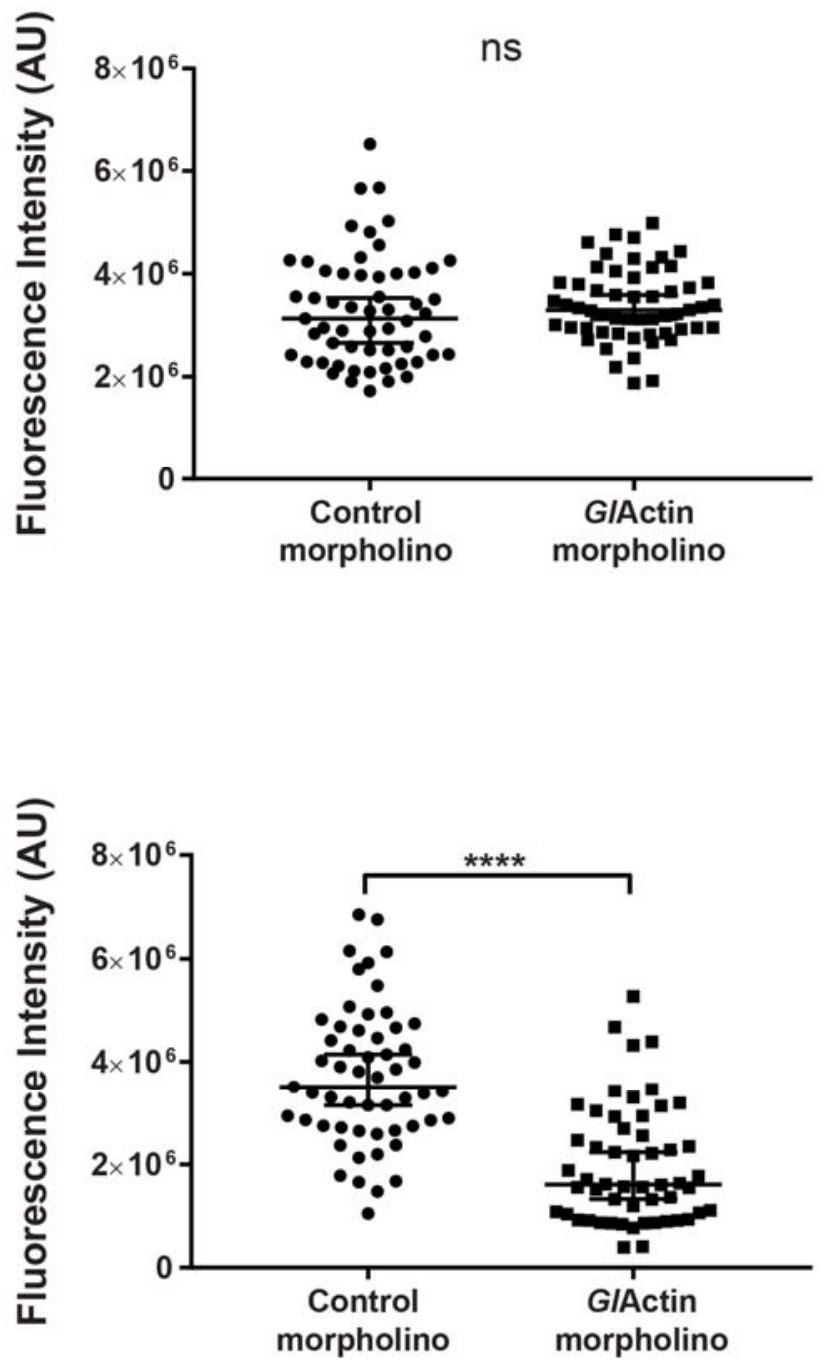

742 Figure 3: DAAP1 loading onto the ventral disc requires GlActin.

743 A) Representative images of attached cells 24 hours after treatment with either an anti-GlActin

744 or control morpholino. Fluorescence intensity of DAAP1 at the ventral groove (see green circle)

745 was measured at the brightest section in each stack. GlActin shown in magenta, mNeonGreen-

746 DAAP1 in green, DAPI in blue. Scale bar denotes $5 \mu \mathrm{m}$. B) A two-tailed Mann-Whitney test

747 indicated that this difference was not statistically significant, $\left(\mathrm{N}_{\text {Control }}=57, \mathrm{~N}_{\text {GlActin-depletd }}=55\right)$, 
$748 \mathrm{P}=0.227$. Median and 95\% confidence interval shown. Median of control=3131445. Median of

749 GlActin-depleted=3298353. Two and four outliers were detected by Tukey Fence, $\mathrm{k}=1.5$ in the

750 control and GlActin-depleted condition respectively and were not included in the analysis. C)

751 Representative images of unattached cells 24 hours after treatment with either an anti-GlActin or

752 control morpholino. Fluorescence intensity of DAAP1 at the ventral groove (see green circle)

753 was measured at the brightest optical section in each stack. D) A two-tailed Mann-Whitney test

754 indicated that this difference was statistically significant, $\left(\mathrm{N}_{\text {Control }}=55, \mathrm{~N}_{\text {GlActin-depletd }}=54\right), \mathrm{P}<0.0001$.

755 Median and 95\% confidence interval shown. Median of control=3508064. Median of GlActin-

756 depleted=1609904. Four outliers were detected by Tukey Fence, k=1.5 in the GlActin-depleted

757 condition and were not included in the analysis. 
A
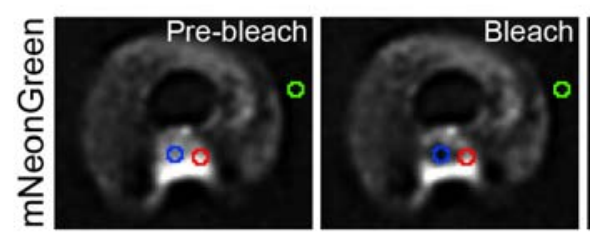

Ventral Groove

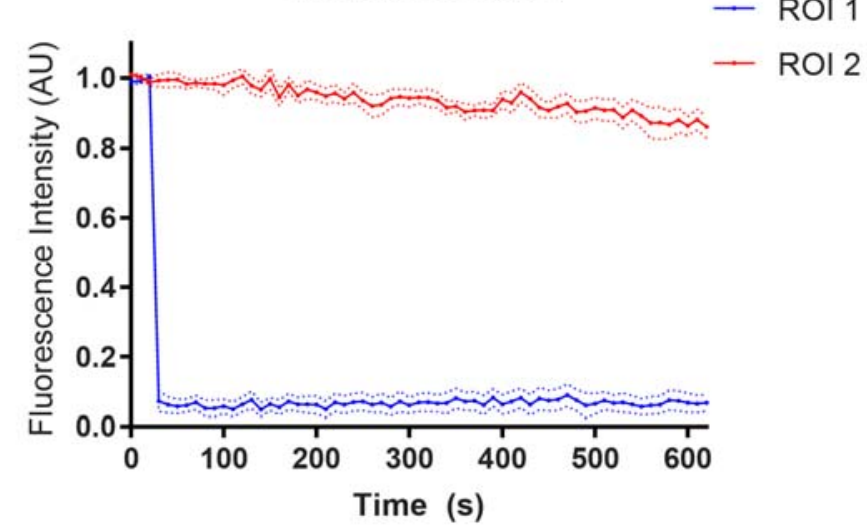

B

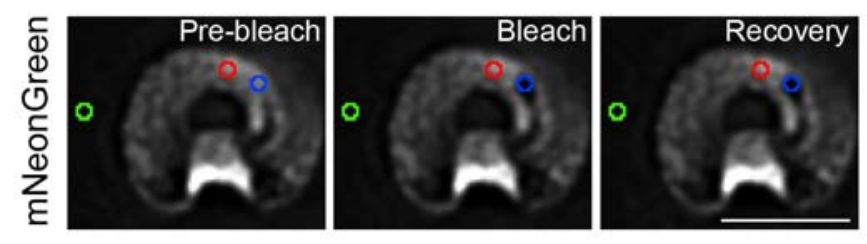

Overlap Zone

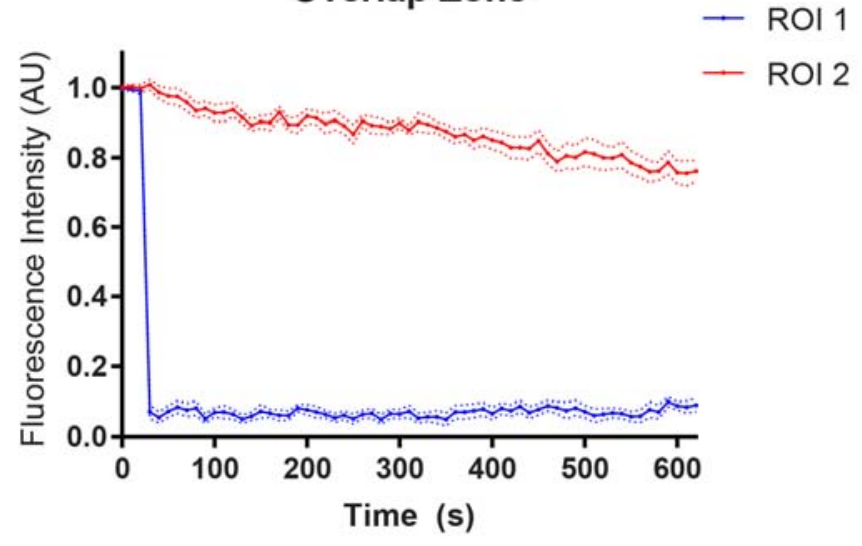

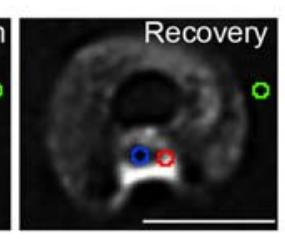

- ROI 1 2 
bioRxiv preprint doi: https://doi.org/10.1101/2021.08.06.455446; this version posted November 24, 2021. The copyright holder for this preprint (which was not certified by peer review) is the author/funder, who has granted bioRxiv a license to display the preprint in perpetuity. It is made available under aCC-BY-NC-ND 4.0 International license.

764 and background (green), and normalized accordingly. Scale bar denotes $5 \mu \mathrm{m}$. N=10 for each

765 ROI in both A and B.

766 
A

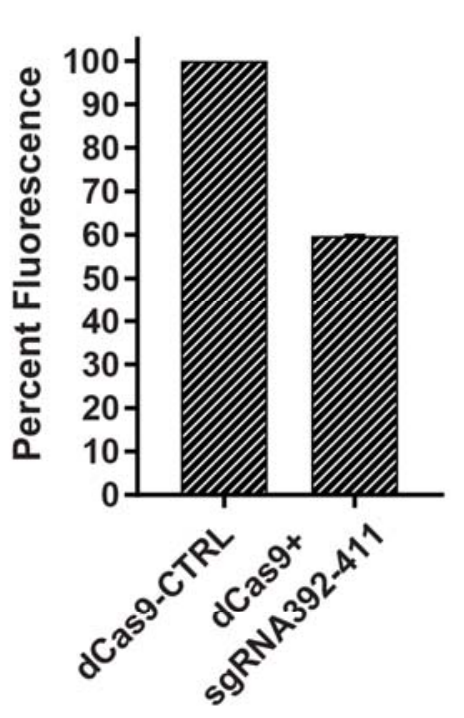

C
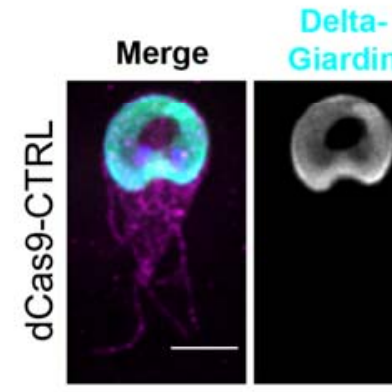
Giardin

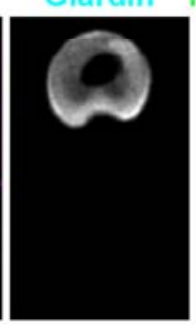

DAAP1mNeonGreen
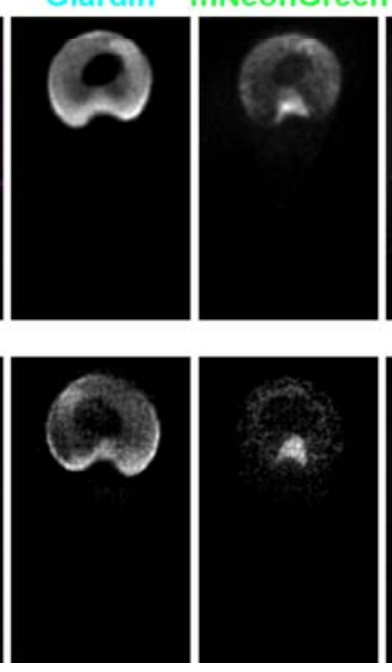

B
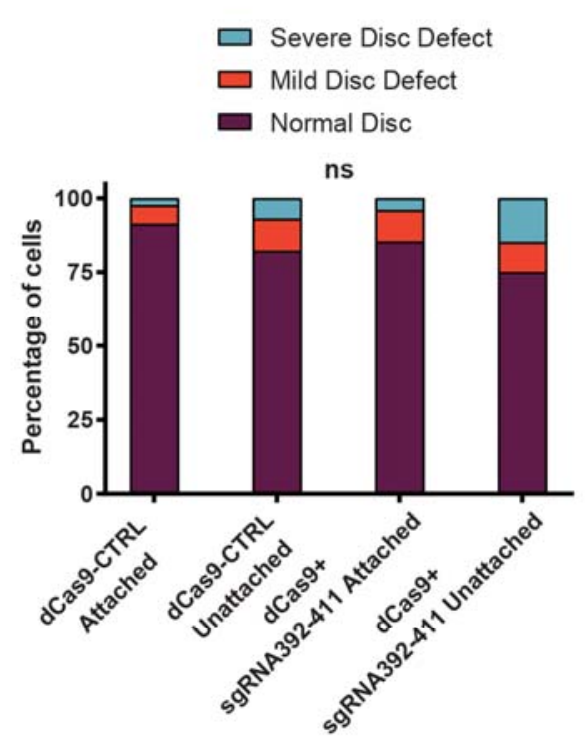

Unattached
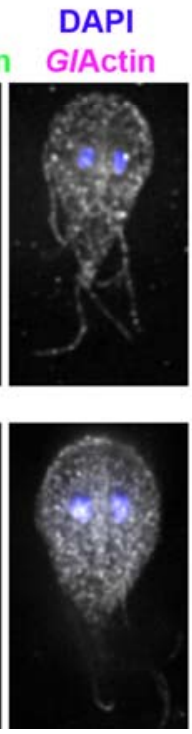

DAAP1 -
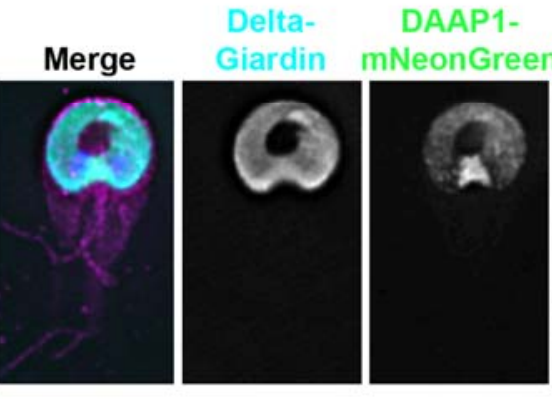

DAPI

GIActin
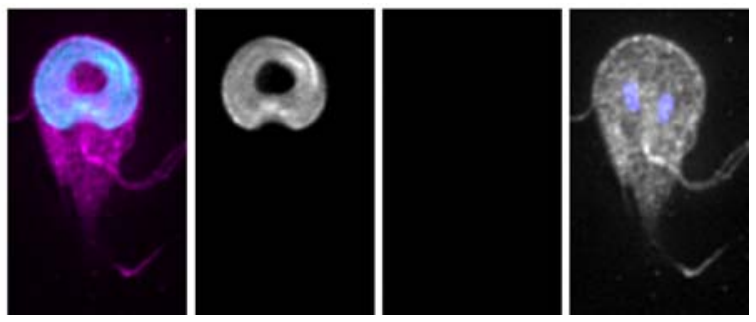

Figure 5: DAAP1-depleted discs do not have defects detectable by light microscopy A.)

769 Fluorescence of DAAP1-mNeonGreen cells transfected with a dead Cas9 vector containing

770 either a non-specific small guide RNA (dCas9-CTRL) or a small guide RNA targeting DAAP1

771 (dCas9+sgRNA392-411). Normalized to the control, the DAAP1-depleted cells demonstrated an

772 average knockdown of $40 \% \pm 3$ (three independent transformations). Attached and unattached

773 control and DAAP1-depleted cells were fixed and stained separately before assessing their disc

774 morphology. Based on a chi-square test, there was no significant difference in disc defects 
775 observed between either attached or unattached groups. (Control attached N=129 cells, control

776 unattached $\mathrm{N}=126$, DAAP1-depleted attached $\mathrm{N}=123$, DAAP1-depleted unattached $\mathrm{N}=128$. .)

777 Attached cells, $\mathrm{P}=0.3483$.Unattached cells:, $\mathrm{P}=0.1288$. C.) Representative images from $\mathrm{B}$ :

778 GlActin (magenta), delta-giardin (cyan), DAAP1 (green), and DAPI/nuclei (blue). Scale bar

779 denotes $5 \mu \mathrm{m}$. 
A

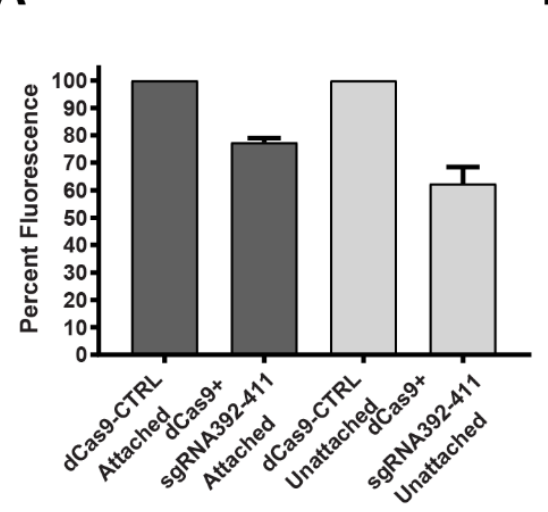

D

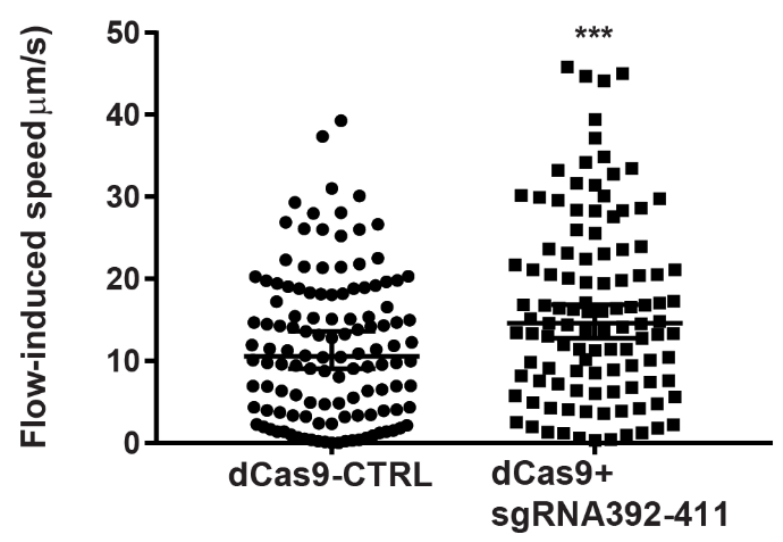

B

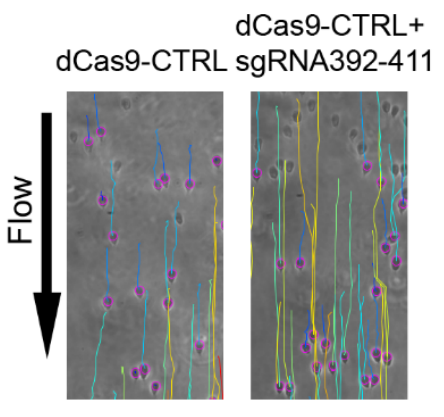

C

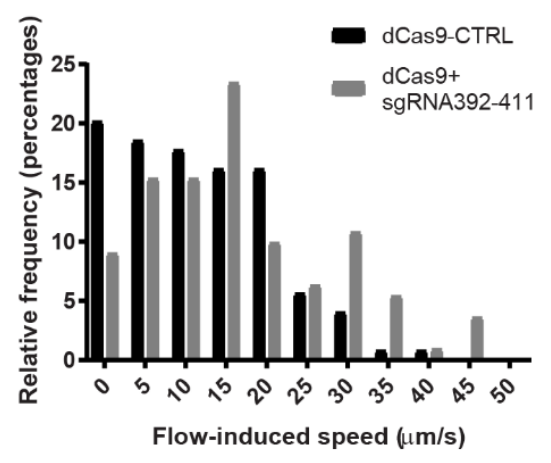

$\mathbf{E}$

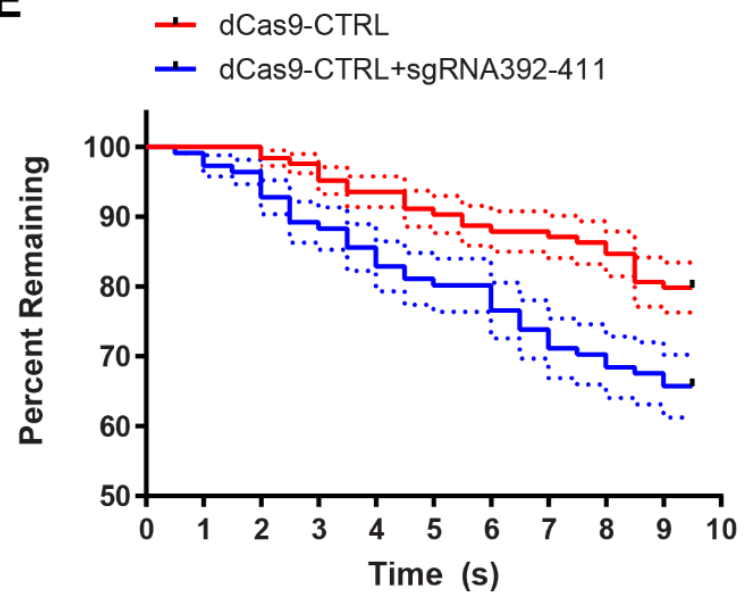

782 Figure 6: DAAP1 depletion results in reduced attachment

783 A) DAAP1 fluorescence levels from control (dCas9-CTRL) and DAAP1-depleted

784 (dCas9+sgRNA392-411). Unattached cells had a greater decrease in DAAP1 expression (38\% \pm

785 6) than attached cells $(23 \% \pm 2)$. Average of two independent transformations with three

786 technical replicates for each is shown. B) In this flow chamber assay, attached cells were

787 challenged with a flow rate of $100 \mu \mathrm{L} / \mathrm{min}$. Cells were tracked for 10 seconds using TrackMate

788 software in ImageJ, colored lines indicating resulting paths. C) Distribution of mean flow-

789 induced speed. D) Mean flow-induced speed of each cell for 10 seconds after challenge, with

790 median and 95\% confidence intervals. A two-tailed Mann-Whitney test indicated that this

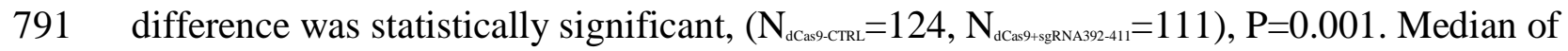

792 control=10.56, upper 95\% CI=13.33, lower 95\% CI=10.15. Median of DAAP1-depleted is 
bioRxiv preprint doi: https://doi.org/10.1101/2021.08.06.455446; this version posted November 24,2021 . The copyright holder for this preprint (which was not certified by peer review) is the author/funder, who has granted bioRxiv a license to display the preprint in perpetuity. It is made available under aCC-BY-NC-ND 4.0 International license.

793 14.62, upper 95\% CI=18.62, lower 95\% CI=14.41. E) Kaplan-Meier curve of cells displaced

794 from the field of view over time, $\mathrm{P}=0.0077 \mathrm{~N}=124$ for control, $\mathrm{N}=111$ for DAAP1-depleted

795 cells. Median and standard error shown.

796 
A

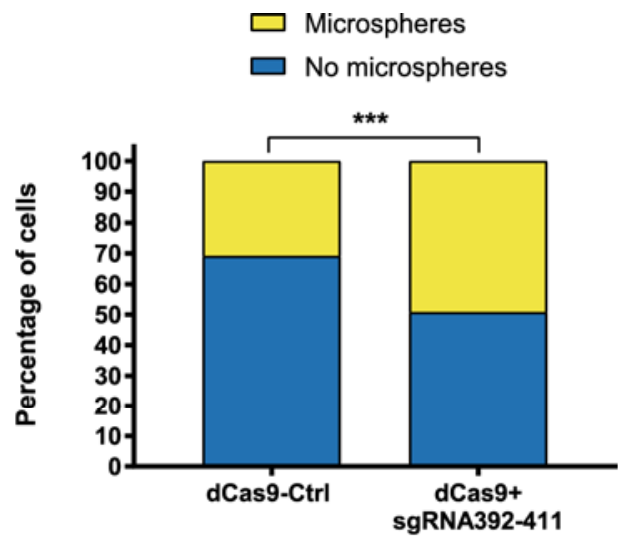

B

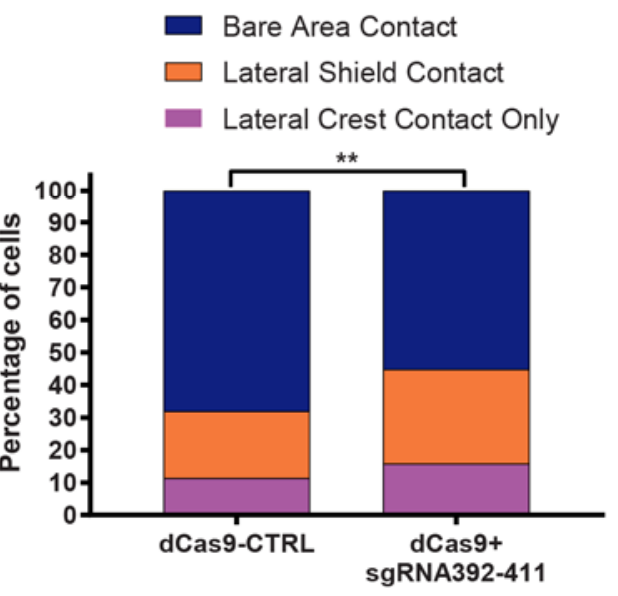

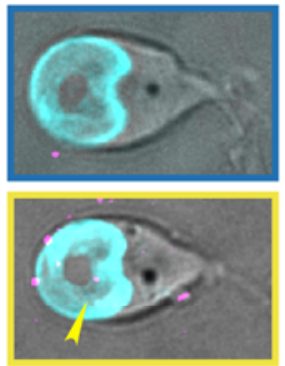

dCas9-CTRL

dCas9+

sgRNA392-411

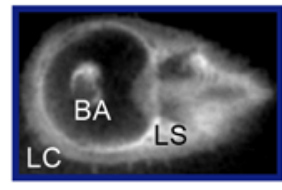

Stage 4:

Fully Attached

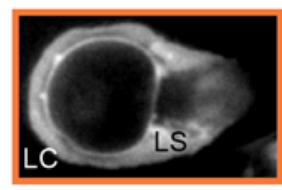

Stage 3:

Partially Attached

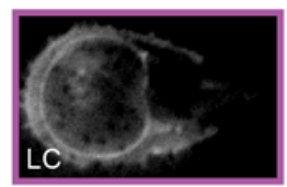

Stage 2:

Initially Attached

\section{Figure 7: DAAP1 has a role in ventral disc seal formation}

800 A.) Fluorescent microspheres were added to live attached control (dCas) and DAAP1-depleted

801 (dCas9+sgRNA392-411) and imaged. Left: significantly more cells with microspheres under the

802 disc were observed in DAAP1-depleted cells based on a chi-square test exact test, $\mathrm{P}<0.001$.

803 N=175 for control, 180 for DAAP1-depleted cells. Right, top: control cell. Right, bottom:

804 DAAP1-depleted cell with microsphere under disc (yellow arrow). Merged images shown with

805 DIC, microspheres (magenta), delta-giardin (cyan). Two-sided Fisher's exact test, $\mathrm{P}=0.0156$ was

806 used for analysis. B.) TIRF microscopy assay to monitor the quality of attachment. Control and

807 DAAP1-depleted cells were stained with the plasma membrane stain CellMask Orange and

808 imaged with TIRF microscopy. Left: significantly more DAAP1-depleted cells were partially 
809 attached than control cells based on a chi-square test, $\mathrm{N}=317$ for each condition, $\mathrm{P}<0.005$. Right:

810 images of cells in initial attachment (stage 2) with lateral crest (LC) contact, partial attachment

811 (stage 3), with lateral crest and lateral shield (LS) contact, or fully attached (stage 4), with lateral

812 crest, lateral shield, and bare area (BA) contact.

\section{Supplemental figure 1: GlActin Depletion by antisense translation-blocking Morpholinos}

815 A) Representative western blot of cells treated with either a standard control morpholino (left) or

816 morpholino targeting GlActin (right) for 24-hours and probed for tubulin (cyan) and GlActin

817 (magenta), resulting in a $\sim 61 \%$ reduction of GlActin levels. B) Average of three morpholino

818 knockdowns results in an average of $50.3 \% \pm 5.6$ reduction of protein expression, as determined

819 by western blot. Values shown are mean \pm SEM.

\section{Supplemental Figure 2: Range of Disc Defect Phenotypes in GlActin-Depleted Cells}

822 A) Representative Giardia cell from the control (attached) condition. (B-E) are GlActin depleted

823 cells with disc defects. Mild defects were categorized as discs which were broken (B) or

824 misshapen (C). Severe defects included unwound discs (D) or disc defects associated with failed

825 cytokinesis $(\mathbf{E})$. All cells pictured in B-E were unattached, with the exception of the bottom row

826 of B. Scale bar denotes $5 \mu \mathrm{m}$.

828 Supplemental Table 1: Raw number of $G l$ Actin-depleted attachment assay cell counts and 829 statistics 
bioRxiv preprint doi: https://doi.org/10.1101/2021.08.06 455446; this version posted November 24, 2021. The copyright holder for this preprint (which was not certified by peer review) is the author/funder, who has granted bioRxiv a license to display the preprint in perpetuity. It is made available under aCC-BY-NC-ND 4.0 International license.

833 Supplemental Table 3: Primer and morpholino sequences and workflow

834

835 Supplemental Table 4: Number of microspheres per cell and statistics

836 